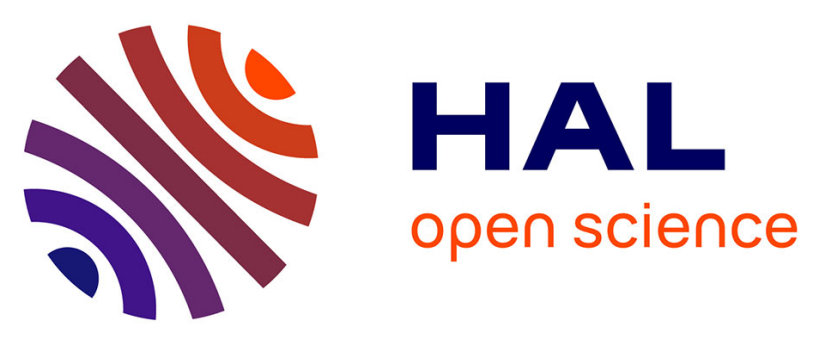

\title{
Improving the Catalytic Performance of Cobalt for CO Preferential Oxidation by Stabilizing the Active Phase through Vanadium Promotion
}

Liping Zhong, Mathias Barreau, Valérie Caps, Vasiliki Papaefthimiou, Michael Haevecker, Detre Teschner, Walid Baaziz, Elisa Borfecchia, Luca Braglia, Spyridon Zafeiratos

\section{To cite this version:}

Liping Zhong, Mathias Barreau, Valérie Caps, Vasiliki Papaefthimiou, Michael Haevecker, et al.. Improving the Catalytic Performance of Cobalt for CO Preferential Oxidation by Stabilizing the Active Phase through Vanadium Promotion. ACS Catalysis, 2021, 11 (9), pp.5369-5385. 10.1021/acscatal.0c05482 . hal-03430796

\section{HAL Id: hal-03430796 https://hal.science/hal-03430796}

Submitted on 16 Nov 2021

HAL is a multi-disciplinary open access archive for the deposit and dissemination of scientific research documents, whether they are published or not. The documents may come from teaching and research institutions in France or abroad, or from public or private research centers.
L'archive ouverte pluridisciplinaire HAL, est destinée au dépôt et à la diffusion de documents scientifiques de niveau recherche, publiés ou non, émanant des établissements d'enseignement et de recherche français ou étrangers, des laboratoires publics ou privés. 


\title{
Improving the Catalytic Performance of Cobalt for CO Preferential Oxidation by Stabilizing the Active Phase through Vanadium Promotion
}

Liping Zhong, Mathias Barreau, Valérie Caps, Vasiliki Papaefthimiou, Michael Haevecker, Detre Teschner, Walid Baaziz, Elisa Borfecchia, Luca Braglia, and Spyridon Zafeiratos*

ACS Catal. 2021, 11, 5369-5385.

https://doi.org/10.1021/acscatal.0c05482

\begin{abstract}
Preferential oxidation of $\mathrm{CO}(\mathrm{COPrOx})$ is a catalytic reaction targeting the removal of trace amounts of $\mathrm{CO}$ from hydrogen-rich gas mixtures. Non-noble metal catalysts, such as $\mathrm{Cu}$ and $\mathrm{Co}$, can be equally active to $\mathrm{Pt}$ for the reaction; however, their commercialization is limited by their poor
\end{abstract}

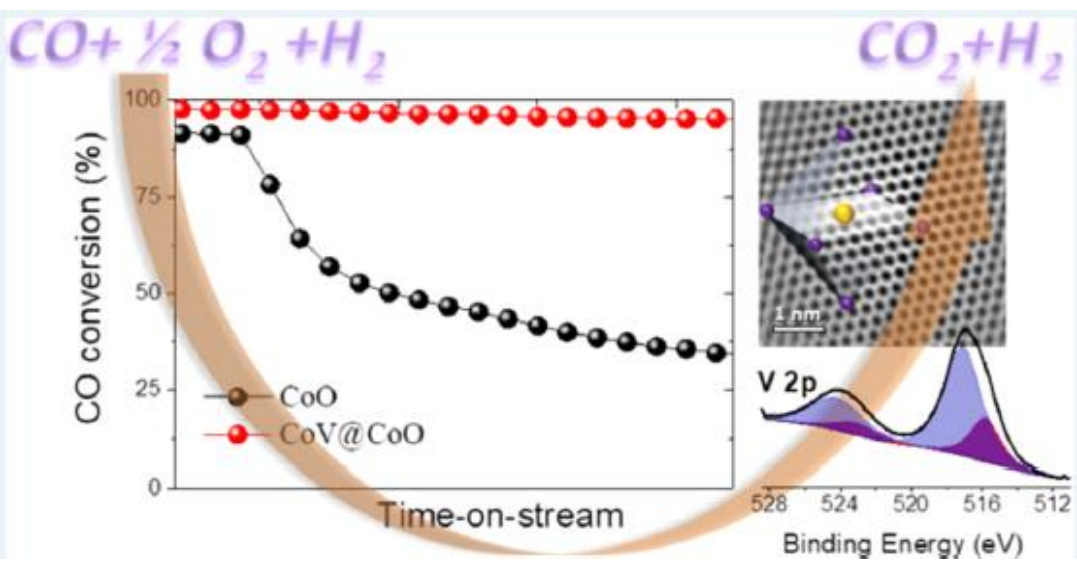
stability. We have recently shown that $\mathrm{CoO}$ is the most active state of cobalt for COPrOx, but under certain reaction conditions, it is readily oxidized to $\mathrm{Co}_{3} \mathrm{O}_{4}$ and deactivates. Here, we report a simple method to stabilize the $\mathrm{Co}^{2+}$ state by vanadium addition. The $\mathrm{V}$ promoted cobalt catalyst exhibits considerably higher activity and stability than pure cobalt. The nature of the catalytic active sites during COPrOx was established by operando NAP-XPS and NEXAFS, while the stability of the $\mathrm{Co}^{2+}$ state on the surface was verified by in situ NEXAFS at 1 bar pressure. The active phase consists of an ultra-thin cobalt-vanadate surface layer, containing tetrahedral $\mathrm{V}^{5+}$ and octahedral $\mathrm{Co}^{2+}$ cations, with an electronic and geometric structure that is deviating from the standard mixed bulk oxides. In addition, V addition helps to maintain the population of $\mathrm{Co}^{2+}$ species involved in the reaction, inhibiting carbonate species formation that are responsible for the deactivation. The promoting effect of $\mathrm{V}$ is discussed in terms of enhancement of $\mathrm{CoO}$ redox stability on the surface induced by electronic and structural modifications. These results demonstrate that V-promoted cobalt is a promising COPrOx catalyst and validate the application of in situ spectroscopy to provide the concept for designing better performing catalysts.

KEYWORDS: COPrOx, cobalt oxides, vanadium oxides, mixed oxides, operando spectroscopy, NAP-XPS, NEXAFS

\section{INTRODUCTION}

Hydrogen, as a clean energy carrier, is the primary fuel for proton-exchange membrane fuel cells (PEMFCs). Although more advanced technologies for hydrogen production are rising, to date, the majority of commercial $\mathrm{H}_{2}$ is still produced by steam reforming of hydrocarbon resources. ${ }^{1,2} \mathrm{H}_{2}$ produced by a steam reforming process followed by water-gas shift contains traces of $\mathrm{CO}_{2}, \mathrm{CO}$, and $\mathrm{CH}_{4}$, which are considered as impurities for PEMFCs. ${ }^{3}$ Among them, $\mathrm{CO}$ is the most critical one, since even $10 \mathrm{ppm}$ of $\mathrm{CO}$ in the feedstock can deactivate the platinum group metal (PGM) catalysts in a PEMFC anode, ${ }^{4,5}$ limiting the credibility of this 
technology. ${ }^{5}$ So far, various technologies have been developed for hydrogen purification. ${ }^{6-9}$ $\mathrm{CO}$ preferential oxidation $(\mathrm{COPrOx})$ in $\mathrm{H}_{2}$ - rich gas is considered as one of the most efficient and straightforward methods for $\mathrm{CO}$ elimination. Apart from precious metals (e.g., Pt and $\mathrm{Au}$ ) that are typically used as catalysts, non-noble metal oxides (e.g., $\mathrm{Cu}$ and $\mathrm{Co}$ oxides), pure or combined with other elements, have shown excellent activity of $\mathrm{CO}$ oxidation in the presence of $\mathrm{H}_{2} \cdot{ }^{10-14}$ Among them, cobalt oxide has attracted wide attention due to its high intrinsic activity toward CO oxidation. ${ }^{15,16}$

Apart from the influences of structure and morphology, surface state has been considered as the dominant factor of the catalytic performance. ${ }^{17,18}$ Typically, COPrOx over reducible metal oxides follows the Mars-van Krevelen reaction mechanism. In particular, initially, CO adsorbs on cationic sites reacting with surface lattice oxygen to form carbonates, which eventually desorb as $\mathrm{CO}_{2}$. Gas-phase $\mathrm{O}_{2}$ regenerates lattice oxygen and closes the catalytic cycle. ${ }^{15,19-22}$ DFT calculations predicted that carbonate decomposition is the rate-limiting step of $\mathrm{CO}$ oxidation on cobalt oxides. ${ }^{23}$ Therefore, although both $\mathrm{Co}_{3} \mathrm{O}_{4}$ and $\mathrm{CoO}$ oxides are active for $\mathrm{CO}$ oxidation, formation and desorption of $\mathrm{CO}_{2}$ are energetically more favorable on $\mathrm{CoO}$ as compared to $\mathrm{Co}_{3} \mathrm{O}_{4}$, hence producing higher reaction rates on $\mathrm{CoO} .{ }^{23-25}$ However, our recent study made clear that $\mathrm{CoO}$ is metastable in $\mathrm{COPrOx}$ reaction conditions and, at certain temperatures, it can be readily oxidized to $\mathrm{Co}_{3} \mathrm{O}_{4}$, leading to deactivation. The $\mathrm{COPrOx}$ reaction temperature seems to be a critical factor of cobalt oxidation since recent studies report that, at higher temperatures, $\mathrm{Co}_{3} \mathrm{O}_{4}$ is rapidly reduced to metallic Co. ${ }^{26-28}$ Metallic $\mathrm{Co}$ is considered inactive for $\mathrm{CO}$ oxidation but has the tendency to catalyze methanation and hydrogen combustion reactions. ${ }^{28,29}$ All the above reports converge to the fact that the cobalt oxidation state is extremely dynamic during the COPrOx reaction and the reactivity is closely related to the redox effect of the gas phase. Durability is an indispensable characteristic of a catalyst; thus, stabilizing the optimum surface oxidation state of a cobalt-based COPrOx catalyst is essential.

The redox ability of cobalt, which is related to the stability of a certain oxidation state, can be modulated by several factors. This includes the particle size and morphology ${ }^{30-32}$ and the choice of the catalytic carrier/support. ${ }^{27}$ The admixture of another metal or oxide, usually referred as a promoter or doping agent, may also be used to influence the redox ability of cobalt. ${ }^{33}$ For example, $\mathrm{CoO}$ may be stabilized in an oxidative atmosphere by the presence of $\mathrm{Pt}^{34,35}$ but needless to say that its high price limits the application of platinum as a promoter. Given that variable-valence metal ions have been regarded as active modifiers able to tune the chemical bond or surface state of metal oxides, we became interested in vanadium-modified cobalt catalysts. Vanadium can easily change between various oxidation states, ${ }^{36}$ and it is known to promote $\mathrm{CO}$ oxidation ${ }^{37}$ and Fischer-Tropsch synthesis ${ }^{38}$ on cobalt. In order to keep the complexity of the catalyst to the minimum possible in order to facilitate the understanding of its function, vanadium was loaded directly onto commercial $\mathrm{CoO}$ nanoparticles, without using a catalytic carrier/support. The catalytic results show that vanadium addition significantly improves both COPrOx activity and stability of CoO. Several ex situ, in situ, and operando characterization methods were used to elucidate the effect of $\mathrm{V}$ promotion on cobalt. The interaction between $\mathrm{Co}$ and $\mathrm{V}$ is examined at the molecular level, and detailed information about the nature of the chemical bond on the catalyst surface is provided. To the best of our knowledge, this paper is the first to report about the superior performance of $\mathrm{V}$ promoted catalyst toward the COPrOx reaction and hopefully can act as a new paradigm for future applications of mixed vanadium-cobalt oxides, which are currently actively exploited in electrocatalysis. ${ }^{39}$ 


\section{EXPERIMENTAL METHODS}

2.1. Catalyst Preparation. Commercial highly pure cobalt oxide nanoparticles (CoO nanoparticles, 99.99\%, Sigma Aldrich) were used as precursors. V-modified cobalt oxides were synthesized by an incipient wetness impregnation method. CoO nanoparticles $(0.9334 \mathrm{~g})$ were post-impregnated in a $\mathrm{NH}_{4} \mathrm{VO}_{3}$ solution $\left(0.18217 \mathrm{~g}\right.$ of $\mathrm{NH}_{4} \mathrm{VO}_{3}(99 \%$, SERLABO) in $0.2 \mathrm{~g}$ of hot water at $75^{\circ} \mathrm{C}$ ) and then manually stirred until the powder of $\mathrm{CoO}$ became all wet. The resulting mixture was then dried in air at $120^{\circ} \mathrm{C}$ for $12 \mathrm{~h}$ and subsequently calcined at $400{ }^{\circ} \mathrm{C}$ for $3 \mathrm{~h}$. The nominal atomic ratio of $\mathrm{V} / \mathrm{Co}$ is kept at $1 / 8(\mathrm{~V} 0.125 \mathrm{Co})$. The surface purity of the catalysts after synthesis was confirmed by X-ray photoelectron spectroscopy (XPS). The ratio of 1:8 between a promoter and cobalt is reported as an optimum content for many promoted Co systems for COPrOx, for example, $\mathrm{Ce}-\mathrm{Co}$ and $\mathrm{Mn}-\mathrm{Co}$ systems; ${ }^{40,41}$ for this reason, this ratio was chosen at first to prepare a V-Co catalyst. Since the catalytic results demonstrated an excellent performance and stability of a $\mathrm{V}_{0.125} \mathrm{Co}$ catalyst as compared to pure cobalt, we did not attempt to further optimize this ratio, but we picked this system for a detailed mechanistic study to understand the role of surface vanadium promotion on cobalt.

2.2. Catalytic Tests. $\mathrm{COPrOx}$ catalytic tests on $\mathrm{CoO}$ and vanadium-modified $\mathrm{CoO}$ catalysts were performed in a fully automated continuous-flow fixed-bed reactor (CETRIB SARL, Andlau, France) under atmospheric pressure; ${ }^{42} 50 \mathrm{mg}$ of the catalyst was loaded into the quartz tube and pretreated in $\mathrm{H} 2\left(30 \mathrm{~mL} \mathrm{~min}^{-1}\right)$ at $400{ }^{\circ} \mathrm{C}$ for $30 \mathrm{~min}$ (heating rate $10{ }^{\circ} \mathrm{C}$ $\mathrm{min}^{-1}$ ), which according to the $\mathrm{TPR}-\mathrm{H}_{2}$ profile (Figure $\mathrm{S} 1$ ) is enough to reduce $\mathrm{CoO}$ to metallic Co. Consequently, the sample was cooled down at $50{ }^{\circ} \mathrm{C}$ and the gas mixture switched to $1 \% \mathrm{CO}, 1 \% \mathrm{O}_{2}$, and $50 \% \mathrm{H}_{2}$ in $\mathrm{He}\left(50 \mathrm{~mL} \mathrm{~min}^{-1}\right)$. The reactants and products were monitored by a compact gas chromatograph (CGC from Interscience, Belgium) equipped with a thermal conductivity detector (TCD) detector. Water in the outlet of the reactor was filtered by a moisture trap before the introduction of the gases in the GC columns. Prior to each test, the pre-reduced catalyst was reduced in situ by heating at $10^{\circ} \mathrm{C} \mathrm{min}^{-1}$ to $400{ }^{\circ} \mathrm{C}$, holding at $400{ }^{\circ} \mathrm{C}$ for $30 \mathrm{~min}$, and cooling back down to $30^{\circ} \mathrm{C}$ under $100 \%$ hydrogen $\left(50 \mathrm{~mL} \mathrm{~min}{ }^{-1}\right.$ total flow). The residual oxygen content of the gas phase was below $100 \mathrm{ppm}$. For light-off tests (increase in the reaction temperature), the catalyst was heated under the COPrOx mixture at $50,100,150,200,250,300$, and $350{ }^{\circ} \mathrm{C}$ using a ramp rate of $10^{\circ} \mathrm{C} \mathrm{min}^{-1}$ and $30 \mathrm{~min}$ dwell at each temperature. For the stability tests (total duration about $6 \mathrm{~h}$ ), the catalyst was heated in $\mathrm{COPrOx}$ at 250 and $300{ }^{\circ} \mathrm{C}$, before cooling down again to $250{ }^{\circ} \mathrm{C}$ (within $15 \mathrm{~min}$ ). The $\mathrm{CO}$ conversion $\left(\mathrm{X}_{\mathrm{CO}}\right)$ and the $\mathrm{CO}$ selectivity to $\mathrm{CO}_{2}\left(\mathrm{~S}_{\mathrm{CO} 2}\right)$ were calculated based on eqs 1 and 2 , respectively: ${ }^{43,44}$

$$
\begin{aligned}
& X_{\mathrm{CO}}(\%)=\frac{[\mathrm{CO}]_{\text {in }}-[\mathrm{CO}]_{\text {out }}}{[\mathrm{CO}]_{\text {in }}} \times 100 \\
& S_{\mathrm{CO} 2}(\%)=\frac{1}{2} \times \frac{[\mathrm{CO}]_{\text {in }}-[\mathrm{CO}]_{\text {out }}}{\left[\mathrm{O}_{2}\right]_{\text {in }}-\left[\mathrm{O}_{2}\right]_{\text {out }}} \times 100
\end{aligned}
$$

In these equations, $[\mathrm{CO}]_{\text {in }},\left[\mathrm{O}_{2}\right]_{\text {in }}$ and $[\mathrm{CO}]_{\text {out }},\left[\mathrm{O}_{2}\right]_{\text {out }}$ are the molar flows of gases at the reactor inlet and outlet, respectively.

2.3. Characterization of Bulk Structure and Morphology. Hydrogen temperatureprogrammed reduction $\left(\mathrm{TPRH}_{2}\right)$ measurements were performed by means of an automated 
characterization system (Micromeritics, model AutoChem II), which incorporates a thermal conductivity detector (TCD). The surface area was determined with a Quantachrome Autosorb-6B surface area analyzer using krypton $(\mathrm{Kr})$ as an adsorbate gas. Samples were degassed at $120{ }^{\circ} \mathrm{C}$ for about $5 \mathrm{~h}$ prior to $\mathrm{Kr}$ adsorption at $77 \mathrm{~K}$, and the specific surface areas were calculated according to the Brunauer-Emmett-Teller (BET) method using 11 data points in the relative pressure $\left(\mathrm{p} / \mathrm{p}_{0}\right)$ range of $0.05-0.3$. The X-ray diffractograms were collected on a Bruker D8 Advance diffractometer, using $\mathrm{Cu} \mathrm{K} \alpha$ radiation $(\lambda=0.15418 \mathrm{~nm})$ between 20 and $90^{\circ}(2 \theta)$, with a step of $0.02^{\circ}$ and a time of $1 \mathrm{~s}$ per step. The morphology of spent and fresh catalysts was examined by a Zeiss GeminiSEM 500 SEM microscope combined with energy-dispersive X-ray spectroscopy (EDS). Scanning transmission electron microscopy (STEM) analysis was carried out using a JEOL 2100 FEG S/TEM microscope operated at $200 \mathrm{kV}$ equipped with a spherical aberration corrector on the probe forming lens. The samples were dispersed by ultrasonication in ethanol and deposited on a holey carboncoated TEM grids. The STEM images were carried out using a spot size of $0.13 \mathrm{~nm}$, a current density of $140 \mathrm{pA}$, and a camera focal length of $8 \mathrm{~cm}$, corresponding to inner and outer diameters of the annular detector of about 73 and $194 \mathrm{mrad}$. Elemental analyses of Co, V, and $\mathrm{O}$ were carried out with an EDS probe using a silicon drift detector (SDD) with a sensor size of $60 \mathrm{~mm}^{2}$.

2.4. Operando Near-Ambient XPS and NEXAFS. The operando synchrotron-based nearambient pressure X-ray photoelectron (NAP-XPS) and near-edge X-ray absorption fine structure spectroscopies (NEXAFS) were performed at the CAT branch of the EMIL beamlines (Energie Materials In-situ Laboratory Berlin) at the synchrotron radiation facility BESSY II of the Helmholtz Zentrum Berlin. ${ }^{45,46}$ The gas-phase composition was monitored on-line by a differentially pumped quadrupole mass spectrometer (QMS, Pfeiffer PrismaPro), which was connected to the experimental cell through a leak valve. The NEXAFS spectra were recorded in the total electron yield (TEY) mode. The catalysts powders were pressed into pellets and placed on a stainless steel plate, which could be heated at the back side by an IR laser. The pellets were initially pretreated in $0.5 \mathrm{mbar}_{2}$ at $400{ }^{\circ} \mathrm{C}$ for $30 \mathrm{~min}$. After the pretreatment, the catalyst was cooled down to room temperature and the reactant gas mixture of $1 \% \mathrm{CO}, 1 \% \mathrm{O}_{2}$, and $50 \% \mathrm{H}_{2}$ in $\mathrm{He}$ of $0.5 \mathrm{mbar}$ was introduced via 4 calibrated mass flow controllers (Bronkhorst) at a total mass flow of $30 \mathrm{~mL} \mathrm{~min}$. The catalysts were initially measured at different temperatures by stepwise heating for about $1 \mathrm{~h}$ in each temperature (light-off measurements). In addition, fresh catalysts after pre-reduction step were measured by directly heating at $250{ }^{\circ} \mathrm{C}$ for about $2 \mathrm{~h}$ to resemble the conditions of the steady-state catalytic tests. XPS spectra of Co 2p, V 2p, O 1s, and C 1s as well as NEXAFS Co L3 and V L3-edges were collected during the reaction. The Co $2 p$ spectra were fitted by a linear combination of peak lineshapes recorded on reference materials ${ }^{47,48}$ using the CASA XPS version 2.3.23 software (more details are provided in the Supporting Information). For the quantitative analysis, the photon flux and the photon-energy dependence of the atomic subshell photoionization cross sections ${ }^{49}$ were taken into account. The XPS Co $2 p$ and V $2 p$ peak intensities were simulated using SESSA version 2.1.1 software $^{50}$ for a model consisting of spherical layered particles with $50 \mathrm{~nm}$ in diameter.

The V L3-edges were simulated using the charge-transfer multiplet (CTM) approach in order to obtain qualitative information from the absorption spectra. ${ }^{51,52}$ The calculations have been performed using the CTM4XAS5.23 program. ${ }^{53}$ The tetrahedral symmetry is chosen for the calculations of $\mathrm{V}^{5+}$ in $\mathrm{Co}_{3} \mathrm{~V}_{2} \mathrm{O}_{8}{ }^{54}$ and $\mathrm{CoVO}_{\mathrm{x}}$ while the octahedral one for $\mathrm{V}^{5+}$ in the $\mathrm{V}_{2} \mathrm{O}_{5.55}$ The crystal field value (10Dq) and the charge transfer energy value $(\Delta)$ were the main parameters adjusted in the simulation to obtain the best accordance with the experimental 
spectra. Other simulation parameters were as follows: (i) for $\mathrm{CoVO}_{\mathrm{x}}$, slater integrals (Fdd, $\mathrm{Fpd}, \mathrm{Gpd})=0.8$, spin-orbit spitting parameter $\mathrm{SO}=1$, optical parameters $\mathrm{Dt}=\mathrm{Ds}=-0.1 \mathrm{eV}$, core hole potential $\mathrm{Upd}$ and the $3 \mathrm{~d}-3 \mathrm{~d}$ repulsion energy $\mathrm{Upd}=\mathrm{Udd}=0.5$, and the hopping parameters eg $=1 \mathrm{eV}$ and $\mathrm{t} 2 \mathrm{~g}=0.7 \mathrm{eV}$; (ii) for the $\mathrm{V}_{2} \mathrm{O}_{5}$ reference, $(\mathrm{Fdd}, \mathrm{Fpd}, \mathrm{Gpd})=1, \mathrm{SO}=$ 1.05, $\mathrm{Upd}-\mathrm{Udd}=2.5$, eg $=1.2 \mathrm{eV}$ and $\mathrm{t} 2 \mathrm{~g}=0.6 \mathrm{eV}$; and (iii) for the $\mathrm{Co}_{3} \mathrm{~V}_{2} \mathrm{O}_{8}$ reference, $(\mathrm{Fdd}, \mathrm{Fpd}, \mathrm{Gpd})=0.75, \mathrm{SO}=1, \mathrm{Dt}=\mathrm{Ds}=-0.1 \mathrm{eV}, \mathrm{Upd}=0, \mathrm{Udd}=1.2, \mathrm{eg}=1.6 \mathrm{eV}$ and $\mathrm{t} 2 \mathrm{~g}=$ 0 .

2.5. In Situ NEXAFS in 1 bar. In situ NEXAFS experiments at 1 bar were performed at the APE-HE beamline of the Elettra synchrotron radiation facility (Trieste, Italy), exploiting a dedicated setup based on a reaction cell with $\mathrm{Si}_{3} \mathrm{~N}_{4}$ membranes, as described in detail elsewhere. ${ }^{56}$ The NEXAFS signal was detected in TEY mode by probing the drain current from the sample with a picoammeter. The catalyst powder was loaded in the in situ cell, installed in the APE-HE instrument, and interfaced with gas delivery and temperature control systems. Gas flows were realized by calibrated mass flow controllers at $50 \mathrm{~mL} \mathrm{~min}{ }^{-1}$. The sample was initially pretreated in $\mathrm{O}_{2}$ at $200{ }^{\circ} \mathrm{C}$ for $15 \mathrm{~min}$ and then cooled to room temperature under $\mathrm{He}$ gas flow to remove adventitious carbon. In situ NEXAFS spectra at Co and V L-edges were then recorded (i) under a reducing atmosphere (pure $\mathrm{H}_{2}$ ) and (ii) exposing the reduced sample to an oxidizing atmosphere $\left(10 \% \quad \mathrm{O}_{2} / \mathrm{He}\right)$ at selected temperatures in the $38-315^{\circ} \mathrm{C}$ range. NEXAFS data were acquired after $15 \mathrm{~min}$ at each selected temperature point. After the reduction step in $\mathrm{H}_{2}$, the sample was cooled down to room temperature in $\mathrm{He}$ gas flow prior to the oxidation step in $10 \% \mathrm{O}_{2} / \mathrm{He}$. Data treatment, involving energy alignment, background subtraction using an asymmetric least squares fitting routine, and normalization to the total area under the curves, was performed by using the recently developed THORONDOR code. ${ }^{57}$

\section{RESULTS}

3.1. Catalytic Performance in COPrOx Reaction. Figure 1 compares the $\mathrm{CO}$ conversion $\left(\mathrm{X}_{\mathrm{CO}}\right)$ and the selectivity to $\mathrm{CO}_{2}\left(\mathrm{~S}_{\mathrm{CO}}\right)$ of pure $\mathrm{CoO}$ (hereafter referred to as $\left.\mathrm{CoO}_{\mathrm{x}}\right)$ and $\mathrm{V}$ modified $\mathrm{CoO}$ (hereafter referred to as $\mathrm{CoVO}_{\mathrm{x}}$ ) catalysts. Prior to the reaction, the samples were reduced at $400{ }^{\circ} \mathrm{C}$. Our previous study showed that reduced cobalt catalysts are more active in COPrOx than their oxidized counterpart. ${ }^{23}$ For both catalysts, XCO increases with the reaction temperature (Figure 1a); however, $\mathrm{X}_{\mathrm{CO}}$ over $\mathrm{CoVO}_{\mathrm{x}}$ is always higher than pure $\mathrm{CoO}_{\mathrm{x}}$. The $\mathrm{CO}_{2}$ selectivity decreases with temperature for both catalysts (Figure 1b). At low temperatures, $\mathrm{CoO}_{\mathrm{x}}$ seems to have a higher $\mathrm{S}_{\mathrm{CO} 2}$ than $\mathrm{CoVO}_{\mathrm{x}}$, while above $250{ }^{\circ} \mathrm{C}$, the trend is reversed. A decrease in $\mathrm{S}_{\mathrm{CO} 2}$ with temperature is common in COPrOx studies of both noble ${ }^{10,58}$ and transition metals. ${ }^{59,60}$ This is attributed to the higher activation energy of the $\mathrm{H}_{2}$ oxidation reaction as compared to the $\mathrm{CO}$ oxidation reaction. ${ }^{14,60,61}$ Therefore, as the temperature increases, the rate of $\mathrm{H}_{2}$ oxidation increases faster, leading to a lower $\mathrm{CO}_{2}$ selectivity. Higher hydrocarbons were not observed in the products, but at high temperatures, methane was detected. Details about methane production can be found in the Supporting Information (see Figure S2 and relevant discussion).

To evaluate their stability, the two catalysts were monitored during COPrOx at 250 and 300 ${ }^{\circ} \mathrm{C}$ for about $6 \mathrm{~h}$ on stream. Note that these tests succeed the temperature tests of Figure $1 \mathrm{a}, \mathrm{b}$ using the same samples after a reduction pretreatment to $400{ }^{\circ} \mathrm{C}$. As shown in Figure $1 \mathrm{c}, \mathrm{d}$, the $\mathrm{X}_{\mathrm{CO}}$ and $\mathrm{S}_{\mathrm{CO} 2}$ remained quite stable in the case of $\mathrm{CoVO}_{\mathrm{x}}$, in contrast to $\mathrm{CoO}_{\mathrm{x}}$, which undergoes rapid deactivation especially at the initial test at $250{ }^{\circ} \mathrm{C}$. The $\mathrm{XCO}$ of $\mathrm{CoO}_{\mathrm{x}}$ at 250 ${ }^{\circ} \mathrm{C}$ decreased rapidly from $90 \%$ to $35 \%$ within about 90 min (Figure $1 \mathrm{c}$ ). The $\mathrm{X}_{\mathrm{CO}}$ increases 
for both catalysts when the temperature increases to $300{ }^{\circ} \mathrm{C}$, but $\mathrm{CoVO}_{\mathrm{x}}$ remains almost $30 \%$ more active than $\mathrm{CoO}_{\mathrm{x}}$. Finally, when the temperature goes back to $250{ }^{\circ} \mathrm{C}$, there is a slight deactivation of $\mathrm{CoVO}_{\mathrm{x}}$ as compared to the $\mathrm{X}_{\mathrm{CO}}$ initially observed, but this sample continues to be considerably more active than pure $\mathrm{CoO}_{\mathrm{x}}$. The superior performance of $\mathrm{CoVO}_{\mathrm{x}}$ also expands in the $\mathrm{CO}_{2}$ selectivity, which is significantly higher for this sample at both temperatures. Overall, the addition of vanadium into cobalt oxide has significantly enhanced the $\mathrm{COPrOx}$ reactivity and $\mathrm{CO}_{2}$ selectivity. Note that pure vanadium oxide is largely inactive for COPrOx (Figure S3); therefore, the dramatic improvement of reactivity can be only ascribed to a synergetic/promotional effect between cobalt and vanadium.
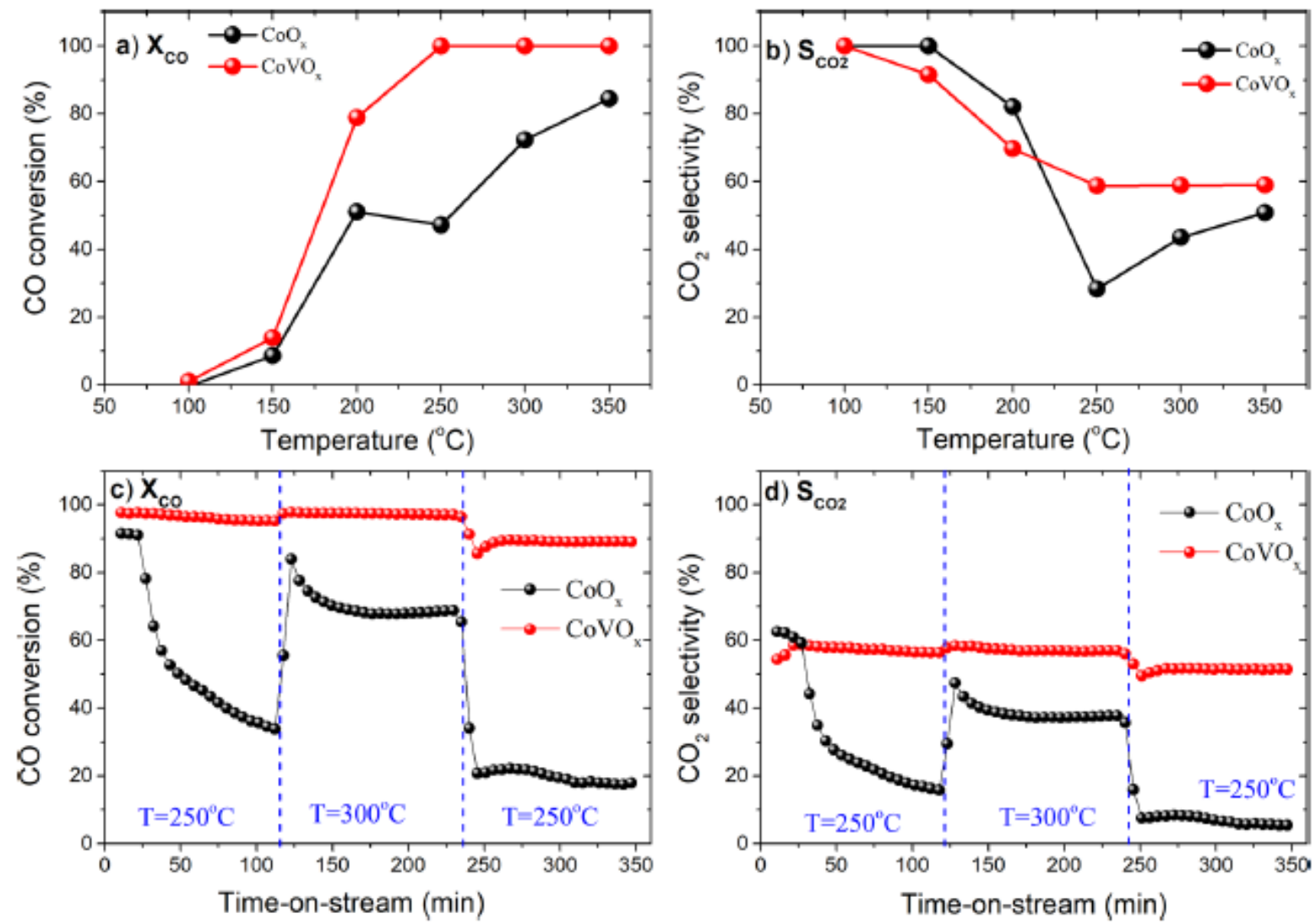

Figure 1. (a) $\mathrm{CO}$ conversion and (b) $\mathrm{CO}_{2}$ selectivity of $\mathrm{CoOx}$ and $\mathrm{CoVOx}$ catalysts as a function of the $\mathrm{COPrOx}$ reaction temperature and (c) $\mathrm{CO}$ conversion and (d) $\mathrm{CO}_{2}$ selectivity as a function of the time-on-stream at two characteristic temperatures. The tests were performed in a fixed bed reactor in $1 \% \mathrm{CO}, 1 \% \mathrm{O}_{2}$, and $50 \% \mathrm{H}_{2}$ in He-balanced flow; $50 \mathrm{mg}$ of catalyst; $50 \mathrm{~mL} / \mathrm{min}$ of total flow at atmospheric pressure.

3.2. Ex Situ Characterization. 3.2.1. Structure and Morphology. The X-ray diffraction (XRD) patterns of fresh, reduced, and spent $\mathrm{CoO}_{\mathrm{x}}$ and $\mathrm{CoVO}_{\mathrm{x}}$ catalysts are shown in Figure S4. The characteristic diffraction peaks of pristine $\mathrm{CoO}_{\mathrm{x}}$ are clearly observed at $2 \theta=36.54$, $42.44,61.53,73.82$, and $77.66^{\circ}$, which correspond to the crystalline planes of (111), (200), (220), (311), and (222) of the face-centered cubic (fcc) CoO phase. ${ }^{62,63}$ Different diffraction peaks appear in the XRD pattern of the as-prepared $\mathrm{CoVO}_{x}$, which are well assigned to the crystallographic planes of $\mathrm{Co}_{3} \mathrm{O}_{4}$ cubic spinel structure (PDF \#76-1802 of the JCPDCS). The $\mathrm{Co}_{3} \mathrm{O}_{4}$ phase formation over $\mathrm{CoVO}_{\mathrm{x}}$ is the result of calcination in air at $400{ }^{\circ} \mathrm{C}$ according to the preparation protocol of this catalyst. After reduction in $\mathrm{H}_{2}$, the XRD patterns of both $\mathrm{CoO}_{\mathrm{x}}$ and $\mathrm{CoVO}_{\mathrm{x}}$ have the same diffraction peaks, which characterize the metallic Co phase. This 
proves that, in their bulk, both catalysts are fully reduced during the reduction treatment preceding the COPrOx. The XRD patterns after reaction (spent catalyst) are very similar to those after $\mathrm{H}_{2}$ treatment, suggesting that metallic Co is preserved in the bulk of the catalysts also under COPrOx. Notably, no additional peaks associated to vanadium compounds are observed in the XRD pattern of the $\mathrm{V}$-modified $\mathrm{CoO}$ sample. The absence of the vanadium phase suggests that the vanadium atoms either form an amorphous oxide or are highly dispersed on the surface of cobalt or even interdiffused in the lattice of cobalt oxide.

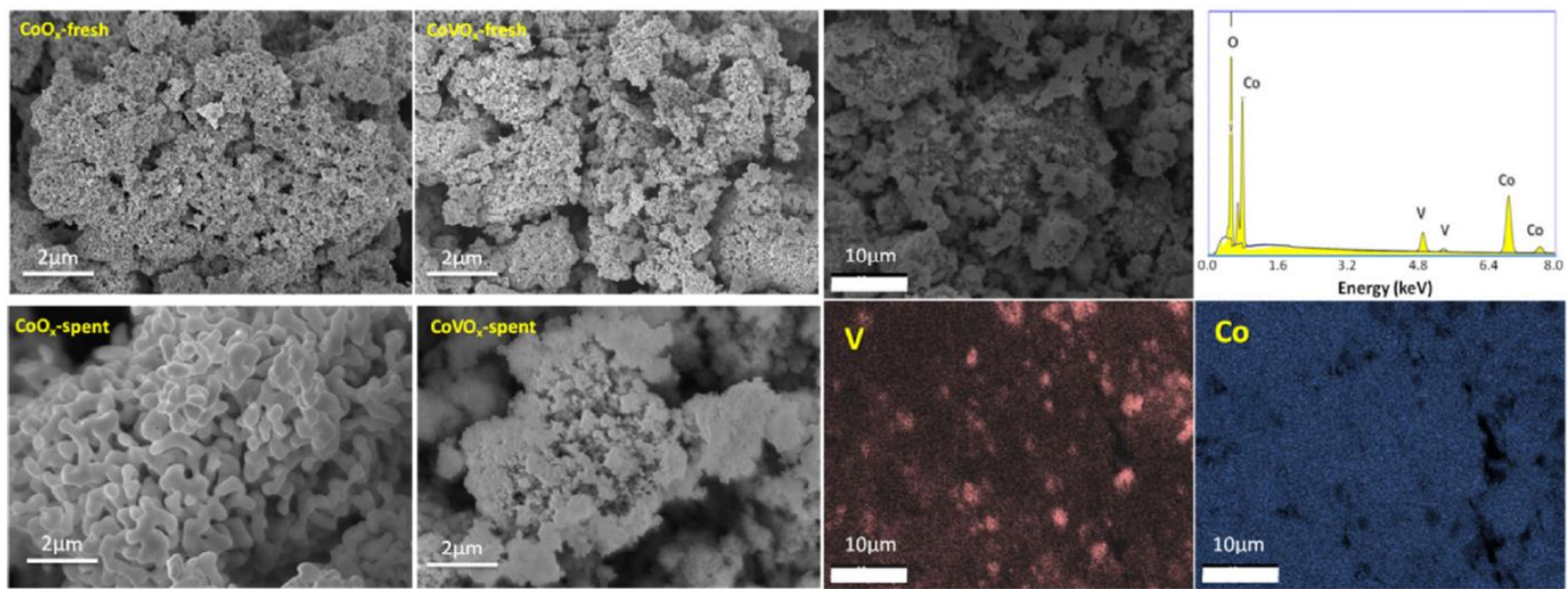

Figure 2. (Left) SEM micrographs of fresh and spent $\mathrm{CoOx}$ and CoVOx catalysts and (right) EDS mapping of fresh CoVOx along with the EDS spectrum recorded from the whole area of the SEM image.

The morphology of fresh and spent catalysts was examined by scanning electron microscopy (SEM). The typical images of fresh and spent samples after $5 \mathrm{~h}$ in the COPrOx reaction at 250 ${ }^{\circ} \mathrm{C}$ as well as energy-dispersive X-ray spectroscopy (EDS) micrographs of the fresh $\mathrm{CoVO}_{\mathrm{x}}$ are shown in Figure 2. SEM images reveal that both fresh $\mathrm{CoO}_{\mathrm{x}}$ and $\mathrm{CoVO}_{\mathrm{x}}$ catalysts consist of similar nanoparticles with sizes between 30 and $60 \mathrm{~nm}$. The typical images of spent catalysts demonstrate the agglomeration of the particles, which should be expected for unsupported metal particles after the long-term stability test at $250{ }^{\circ} \mathrm{C}$. The EDS mapping shows that vanadium is distributed all over the entire surface of cobalt, while some homogeneously dispersed particles with a diameter of around 1-2 $\mu \mathrm{m}$ can be also distinguished in the vanadium EDS image. The \% at. of V calculated from the EDS spectrum corresponding to this SEM image is $11 \%$, which is in good agreement with the nominal $\mathrm{V}$ loading on the catalyst (12.5\%).

Figure 3a shows a typical annular bright-field (ABF) and high-angle annular dark-field (HAADF) scanning transmission electron microscopy (STEM) images of the $\mathrm{CoVO}_{\mathrm{x}}$ catalyst after $5 \mathrm{~h}$ COPrOx at a $250{ }^{\circ} \mathrm{C}$ reaction (spent catalyst). Additional STEM images of the spent catalyst, as well as just after reducing pretreatment and before the catalytic tests, can be found in Figures S5a and S5b. The ABF-STEM image shows aggregated $\mathrm{CoVO}_{\mathrm{x}}$ nanoparticles with a size of around $50 \mathrm{~nm}$. The presence of darker regions inside the particles is clearly visible in the HAADF-STEM image. Since, in HAADF mode, the contrast is directly related to the atomic number and the material density, one can assume that the darker regions are cavities or voids with a mean size of about $10 \mathrm{~nm}$. Interestingly, as depicted by Figure $3 \mathrm{a}$, the cavities have a round shape. Similar morphologies have been observed also in our previous work on pure cobalt oxides. ${ }^{23}$ 
Aiming at locating $\mathrm{V}$ in the catalyst grains, a complementary analysis was carried out using STEM combined with EDS. The STEM-EDS maps of an aggregate with about $60 \mathrm{~nm}$ in diameter are presented in Figure 3b. Elemental mapping reveals significant overlap between $\mathrm{V}$ and Co, suggesting that $\mathrm{V}$ is well distributed all over the Co particles. Although this is the most common arrangement of the catalyst (see Figure S5), sometimes STEM-EDS images with separated Co and V could be also depicted (not shown here). A clearly visible feature in the STEM-EDS image that combines Co and V signals (Figure 3b) is that the V content is increasing at the edge of the particle, suggesting that $\mathrm{V}$ is enriched on the surface of the grains. However, the Co signal is extending to the perimeter of the aggregate overlapping with $\mathrm{V}$, which is strong evidence that the two elements are not segregated in the near surface area but most probably they are mixed together. Interestingly, in the XRD patterns of spent $\mathrm{CoVO}_{\mathrm{x}}$ shown in Figure S4, there are no features related to vanadium, demonstrating the absence of such phases in the bulk. In accordance to the STEM-EDS analysis, this can be justified by highly distributed vanadium around the cobalt particles and/or the formation of an amorphous vanadium oxide layer.
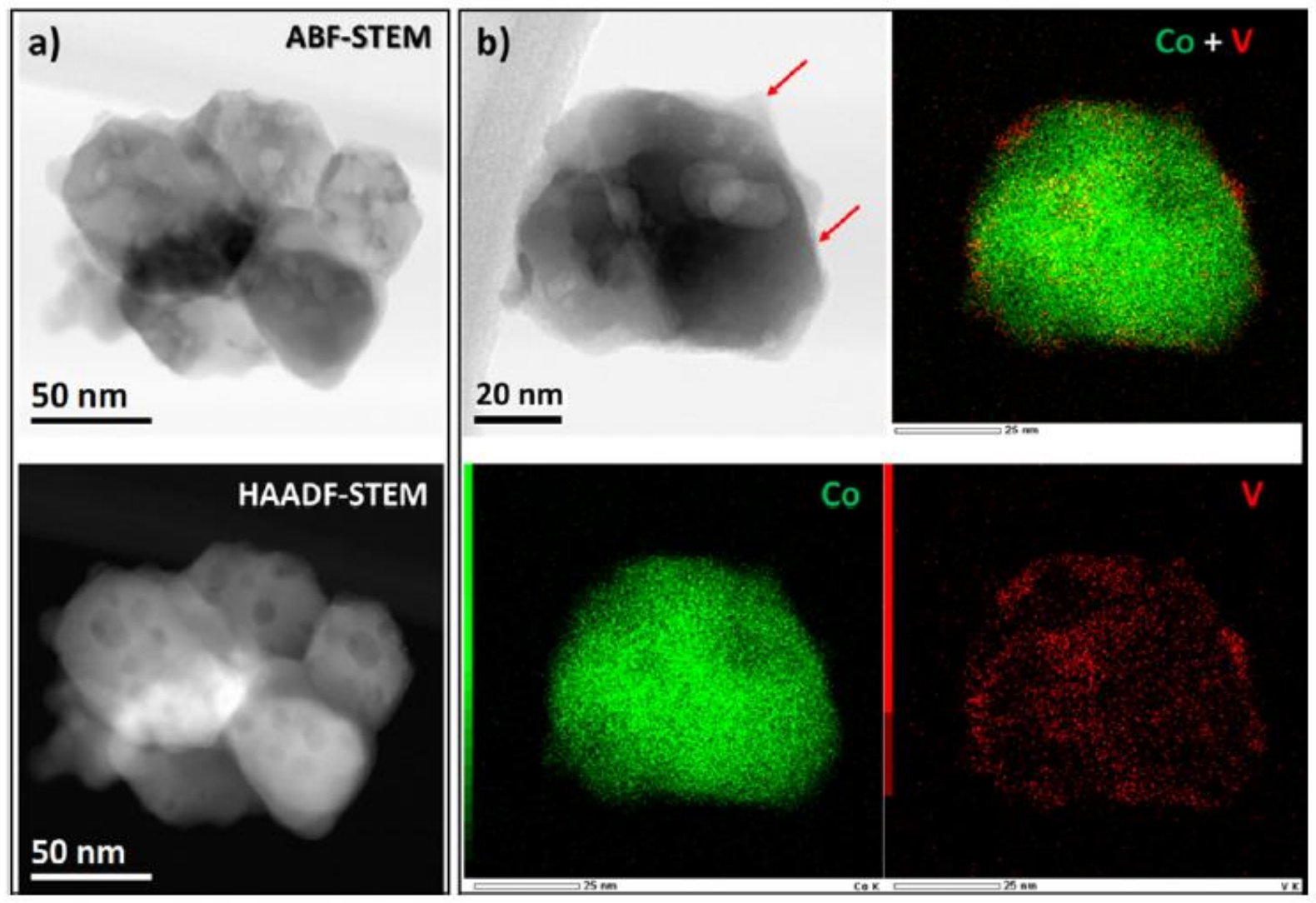

Figure 3. (a) ABF-STEM and the corresponding HAADF-STEM and (b) STEM-EDS analysis images with elemental mapping ( $\mathrm{Co}$ and $\mathrm{V}$ and merged $\mathrm{Co}+\mathrm{V})$. The images were collected over the spent $\mathrm{CoVO}_{\mathrm{x}}$ catalyst after a $5 \mathrm{~h}$ reaction at $250{ }^{\circ} \mathrm{C}$ in a 1 bar $\mathrm{COPrOx}$ mixture.

Fine details of the near surface area of the $\mathrm{CoVO}_{x}$ catalyst are given by high-resolution STEM (HR-STEM). Figure 4 presents a characteristic HR-STEM micrograph collected at the external surface of the spent $\mathrm{CoVO}_{\mathrm{x}}$ catalyst. Similar micrographs of another catalytic particle can be found in Figure S5c. The separation distances between sets of parallel planes close to the surface $\left(\mathrm{d}_{\mathrm{hkl}}\right)$ were measured in higher magnification images and compared with known $\mathrm{d}_{\mathrm{hkl}}$ values of cobalt and vanadium oxides. Measurements in several areas well resolved at the 
HR-STEM images suggest two $\mathrm{d}_{\mathrm{hkl}}$ distances of 0.25 and $0.29 \mathrm{~nm}$. These distances match with the (311) and (220) planes, respectively, of $\mathrm{Co}_{3} \mathrm{O}_{4}$ (JCPDS 03-065-3103) and binary mixed $\mathrm{Co}_{3} \mathrm{~V}_{2} \mathrm{O}_{8}$ (JCPDS 00-016-0675), along with the (130) and (013) planes of Co2V2O7 (JCPDS 00-029-0519). Monoclinic and orthorhombic $\mathrm{V}_{2} \mathrm{O}_{5}$ crystal as well as $\mathrm{CoO}$ do not fit with the measured dhkl distances and should be excluded. Although HR-STEM cannot be conclusive about the composition of the surface layer, the possibility of a mixed $\mathrm{Co}-\mathrm{V}$ oxide formation is in line with the surface-sensitive spectroscopic results, as will be discussed later.

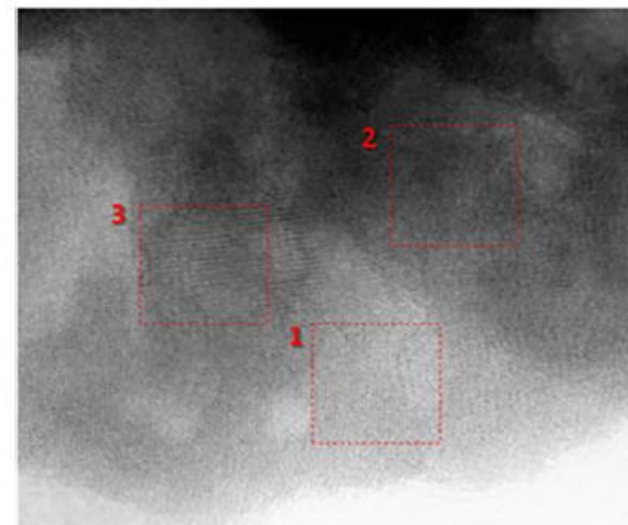

$10 \mathrm{~nm}$

Figure 4. High-resolution ABF-STEM and the corresponding FFT filtered images (bottom right) of spent $\mathrm{CoVO}_{x}$ catalysts derived from catalyst areas close to the particle edge. The interplanar spacing is indicated by two parallel lines. The squares indicate the part of the low magnification image from which the high-resolution images are derived.

3.2.2. BET and TPR. The BET specific surface area measurements of reduced and spent $\mathrm{CoO}_{\mathrm{x}}$ and $\mathrm{CoVO}_{\mathrm{x}}$ catalysts are presented in Table 1. After reduction, pure $\mathrm{CoO}_{\mathrm{x}}$ has a significantly lower surface area than $\mathrm{CoVO}_{x}$, even though $\mathrm{CoO}$ particles from the same batch were initially used for the $\mathrm{CoVO}_{\mathrm{x}}$ and $\mathrm{CoO}_{\mathrm{x}}$ preparation. This demonstrates that sintering and agglomeration of cobalt nanoparticles upon the reducing thermal treatment is moderated by the addition of $\mathrm{V}$, in agreement with SEM images shown in Figure 2. Another interesting observation is that the surface area increases after the reaction, as compared to the reduced catalyst, which, according to the low magnification STEM images shown in Figure S5b, is due to improvement in the dispersion of the catalytic particles.

Temperature-programmed reduction (TPR) was used to investigate the effect of V addition to cobalt oxide reducibility. The TPR profile (Figure S1) of pure CoOx after calcination in air is characterized by two main features (peaks), which represent a two-stage reduction process $\mathrm{Co}_{3} \mathrm{O}_{4} \rightarrow \mathrm{CoO} \rightarrow \mathrm{Co}$, in good agreement with previous reports. ${ }^{37,64}$ The TPR profile of the $\mathrm{CoVO}_{\mathrm{x}}$ catalyst shows a number of additional peaks shifted to higher temperatures as compared to $\mathrm{CoO}_{\mathrm{x}}$. Although the attribution of each feature in the TPR profile of $\mathrm{CoVO}_{\mathrm{x}}$ is not straightforward since it involves reduction of both $\mathrm{V}$ and Co oxide species as well as their interfaces, the higher reduction temperature implies a strong interaction between cobalt and vanadium, resulting in a material that is more difficult to reduce. ${ }^{65}$ The TPR profiles are related to bulk reduction, and therefore it is hard to correlate them with the catalytic performance. The differences in the reducibility of the surfaces of the two catalysts will be defined in more detail based on the operando spectroscopic results presented below. 
Table 1. Surface Area of $\mathrm{CoO}_{x}$ and $\mathrm{CoVO}_{x}$ Catalysts Measured by Kr-BET, Just before (Reduction in $\mathrm{H}_{2}$ for $30 \mathrm{Min}$ at $400{ }^{\circ} \mathrm{C}$ ) and after the COPrOx Reaction (Spent) at $250{ }^{\circ} \mathrm{C}$ for 90 Min

$$
\mathrm{CoO}_{x}\left(\mathrm{~m}^{2} \mathrm{gr}^{-1}\right) \quad \mathrm{CoVO}_{x}\left(\mathrm{~m}^{2} \mathrm{gr}^{-1}\right)
$$
reduced catalyst (before reaction)
1.39
9.57
spent catalyst (after reaction)
1.79
16.05
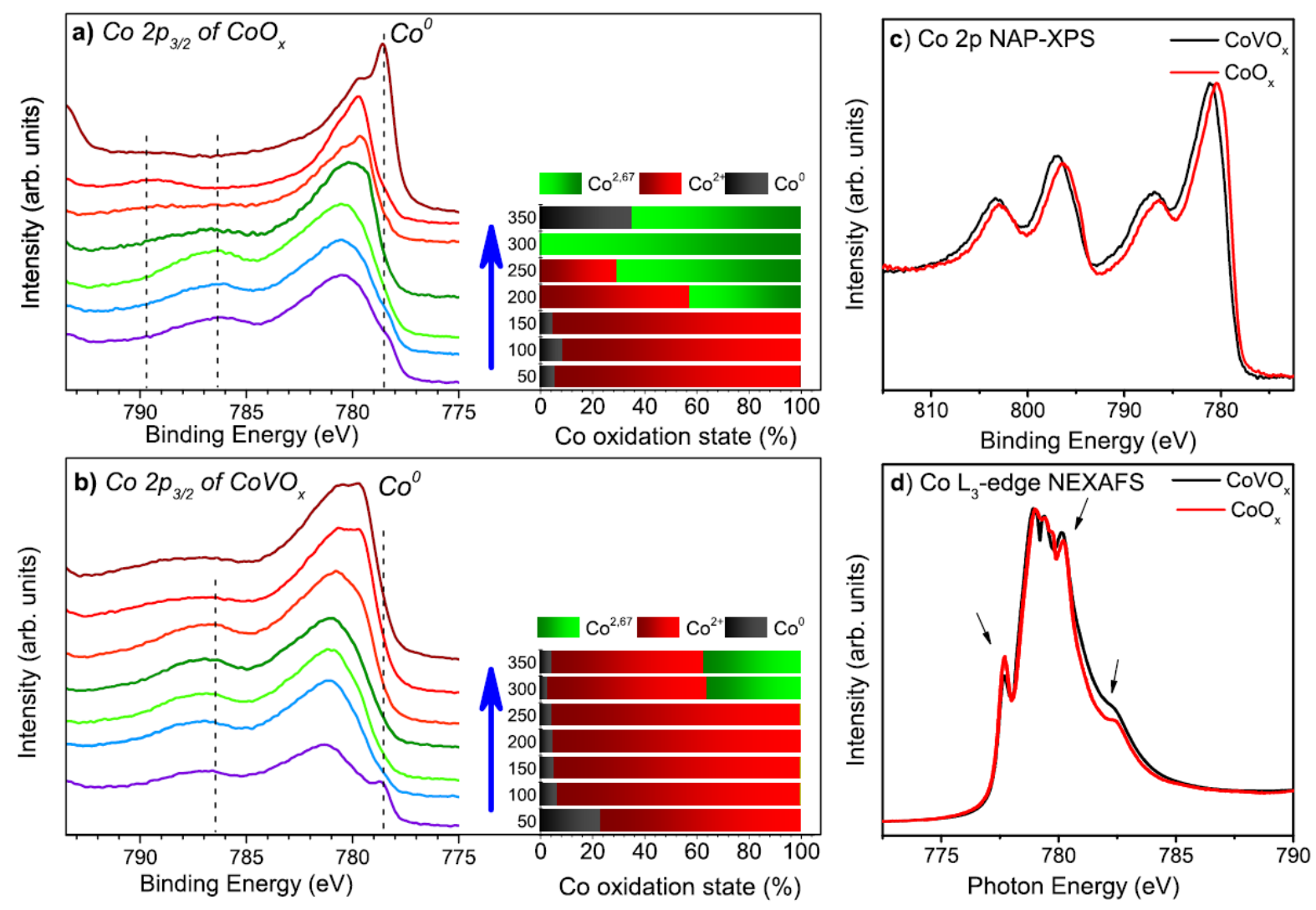

Figure 5. Operando NAP-XPS spectra of Co $2 \mathrm{p}_{3 / 2}$ over $\mathrm{CoOx}$ (a) and $\mathrm{CoVOx}$ (b) catalysts recorded at different temperatures during the COPrOx reaction: $1 \% \mathrm{CO}, 1 \% \mathrm{O}_{2}$, and $50 \% \mathrm{H}_{2}$ in $\mathrm{He}$, at 0.5 mbar total pressure. Each spectrum was recorded after about $10 \mathrm{~min}$ in the reaction feed. The distribution of cobalt species obtained by Co $2 p$ peak deconvolution is shown in the inset bar graphs. For clarity, all spectra are normalized to the same intensity and offset to the $y$ axis. (c) Co 2p NAP-XPS and (d) Co L3-edge NEXAFS spectra of $\mathrm{CoO}_{x}$ and $\mathrm{CoVO}_{\mathrm{x}}$ catalysts in conditions that favor the formation of the $\mathrm{Co}^{2+}$ state, i.e., at $150{ }^{\circ} \mathrm{C}$ in the COPrOx mixture. Co $2 p$ and Co L3-edge spectra are normalized to the same intensity.

\subsection{Comparative Operando NAP-XPS and NEXAFS at 0.5 mbar. 3.3.1. The Oxidation} State of Cobalt. Several previous reports have demonstrated that the surface oxidation state of cobalt plays a key role for COPrOx reactivity. ${ }^{23,66,67}$ At low temperatures, the COPrOx mixture can oxidize metallic cobalt, whereas at relatively high temperatures, cobalt oxides could be reduced back to metal. ${ }^{26,27,68}$ Thus, depending on the COPrOx reaction conditions, cobalt may easily swap between different oxidation states. Herein, synchrotron-based NAPXPS and NEXAFS were used to monitor, on a comparative basis, the surface oxidation state 
of $\mathrm{CoO}_{\mathrm{x}}$ and $\mathrm{CoVO}_{\mathrm{x}}$ during the $\mathrm{COPrOx}$ reaction. Light-off and time-on-stream experiments were performed following an experimental protocol similar to the catalytic tests shown in Figure 1. Fresh samples, retrieved from the same synthesis batch, were used in each case. Prior to the reaction, the samples were pre-reduced at $400{ }^{\circ} \mathrm{C}$ in $0.5 \mathrm{mbar} \mathrm{H}_{2}$ for $30 \mathrm{~min}$.

Figure 5 shows the evolution of $\mathrm{Co} 2 \mathrm{p}_{3 / 2}$ spectra as a function of COPrOx reaction temperature for $\mathrm{CoO}_{\mathrm{x}}$ (Figure 5a) and $\mathrm{CoVO}_{\mathrm{x}}$ (Figure 5b) catalysts. Deconvolution of the spectra using reference peaks was used to quantify the various oxidation states of cobalt (see Figure S6 and relevant discussion). At $50{ }^{\circ} \mathrm{C}$, the main $\mathrm{Co} 2 \mathrm{p}_{3 / 2}$ peak of the $\mathrm{CoO}_{\mathrm{x}}$ catalyst (Figure 5a) is centered at $780.5 \mathrm{eV}$ with a satellite peak around $786.7 \mathrm{eV}$ characteristic of $\mathrm{Co}^{2+}$ species. ${ }^{30,31,62,69,70}$ The shoulder at $778.6 \mathrm{eV}$ is induced by metallic $\mathrm{Co},{ }^{62,71-73}$ indicating that cobalt forms a mixed $\mathrm{Co}^{0} / \mathrm{CoO}$ phase in $\mathrm{COPrOx}$, in accordance with our previous findings.23 As the reaction temperature increases, cobalt is further oxidized into $\mathrm{Co}_{3} \mathrm{O}_{4}$ (with an average oxidation state $\mathrm{Co}^{2.67+}$ ) identified by a broad satellite at $789.5 \mathrm{eV}$ clearly indexed at $300{ }^{\circ} \mathrm{C} .70$ However, at $350{ }^{\circ} \mathrm{C}$, the low binding energy (BE) peak appears again in the Co $2 \mathrm{p}_{3 / 2}$ spectrum, indicating that part of $\mathrm{Co}_{3} \mathrm{O}_{4}$ is reduced back to metallic Co. This is an intriguing observation showing that the redox effect of COPrOx mixture on cobalt surface is controlled by the reaction temperature.

In the case of $\mathrm{CoVO}_{\mathrm{x}}$ (Figure $5 \mathrm{~b}$ ), a mixed $\mathrm{Co}^{0} / \mathrm{Co}^{2+}$ oxidation state is found at $50{ }^{\circ} \mathrm{C}$, while at $150{ }^{\circ} \mathrm{C}$, the surface is dominated by $\mathrm{Co}^{2+}$, likewise to the $\mathrm{CoO}_{\mathrm{x}}$ sample. However, above this temperature, the stability of $\mathrm{Co}^{2+}$ species is distinctly different between the two catalysts. In particular, as clearly shown in the bar graphs, over $\mathrm{CoVO}_{\mathrm{x}}$, the $\mathrm{Co}^{2+}$ phase is stabilized up to $250{ }^{\circ} \mathrm{C}$, while partial oxidation to $\mathrm{Co}^{2.67+}$ is observed only above $300{ }^{\circ} \mathrm{C}$. Contrary to $\mathrm{CoO}_{\mathrm{x}}$, the sample is not reduced to metallic $\mathrm{Co}^{0}$ at $350{ }^{\circ} \mathrm{C}$. Notably, $\mathrm{Co}^{2+}$ is a dominant $\mathrm{CoVO}_{\mathrm{x}}$ surface phase at intermediate reaction temperatures (ca. $250^{\circ} \mathrm{C}$ ), which are actually of main interest for $\mathrm{COPrOx}$ since higher temperatures promote the undesired water and methane formation. ${ }^{23,60}$

NEXAFS is a powerful technique to study the electronic and geometric structure of materials in an element-specific fashion. ${ }^{74}$ Moreover, contrary to XRD, it is surface-sensitive (probing depth in the order of 5-10 nm with TEY detection) ${ }^{55}$ and can detect both crystalline and amorphous phases. ${ }^{75-77}$ The operando NEXAFS spectra presented in Figure S7 confirm the higher stability of $\mathrm{Co}^{2+}$ species over the $\mathrm{CoVO}_{\mathrm{x}}$ catalyst observed in NAP-XPS. In addition to that, the characteristic lineshape of octahedrally coordinated $\mathrm{Co}^{2+}$ can be clearly distinguished at intermediate temperatures in both samples. This result implies that the octahedral symmetry of $\mathrm{Co}^{2+}$ ions does not change by $\mathrm{V}$ addition, in contrast to other promoters, e.g., Zn, which tend to stabilize tetrahedral $\mathrm{Co}^{2+}$ species. $^{78}$

In an attempt to identify minor differences in the electronic structure of $\mathrm{Co}^{2+}$ species in the two cases, we compare in Figure $5 \mathrm{c}$ the Co $2 \mathrm{p}$ spectra of the two catalysts at conditions where the $\mathrm{Co}^{2+}$ species dominate. Despite the similar peak profiles, the spectrum of $\mathrm{CoVO}_{\mathrm{x}}$ is shifted by about $0.6 \mathrm{eV}$ with respect to $\mathrm{CoO}_{\mathrm{x}}$. This shift is also observed for Co $2 \mathrm{p}$ spectra recorded at different photon flux conditions and is not due to electrostatic charging, considering the identical position of the $\mathrm{C} 1 \mathrm{~s}$ peak of the two samples (see below). In addition, the shift between the spectra is also visible in partially reduced $\mathrm{CoO}_{\mathrm{x}}$ and $\mathrm{CoVO}_{\mathrm{x}}$ where the sharp photoelectron peak of $\mathrm{Co}^{0}$ was used as an internal reference (see Figure S8). The Co $2 \mathrm{p}_{3 / 2}$ shift to higher binding energies is consistent with earlier studies of cobalt vanadates; ${ }^{79-82}$ however, the magnitude of the energy shift $(0.6 \mathrm{eV})$ observed here is lower than the previous reports. 
The Co L3-edges corresponding to the photoelectron peaks (Figure 5d) are characteristic of octahedrally coordinated $\mathrm{Co}^{2+}$ species ${ }^{34,70,83}$ as mentioned above. Although the two spectral lineshapes overlap, in the case of $\mathrm{CoVO}_{x}$, there is a relatively lower intensity of the peak at $777.7 \mathrm{eV}$ and higher at the features around 780.1 and $781.8 \mathrm{eV}$ (pointed out by arrows). Changes in the NEXAFS spectra indicate deviation in the ligand-field-related Co $3 \mathrm{~d}$ electronic states of the two catalysts, despite the same symmetry. This can be caused by differences in the $\mathrm{Co}-\mathrm{O}$ bond length, angle, and strength, as well as the interaction of cobalt ions with $\mathrm{V}$ heteroatoms. ${ }^{84,85}$ Similar changes in the Co L3-edge of cobalt-halogen compounds have been attributed to the increase in cobalt ion electronegativity. ${ }^{84}$
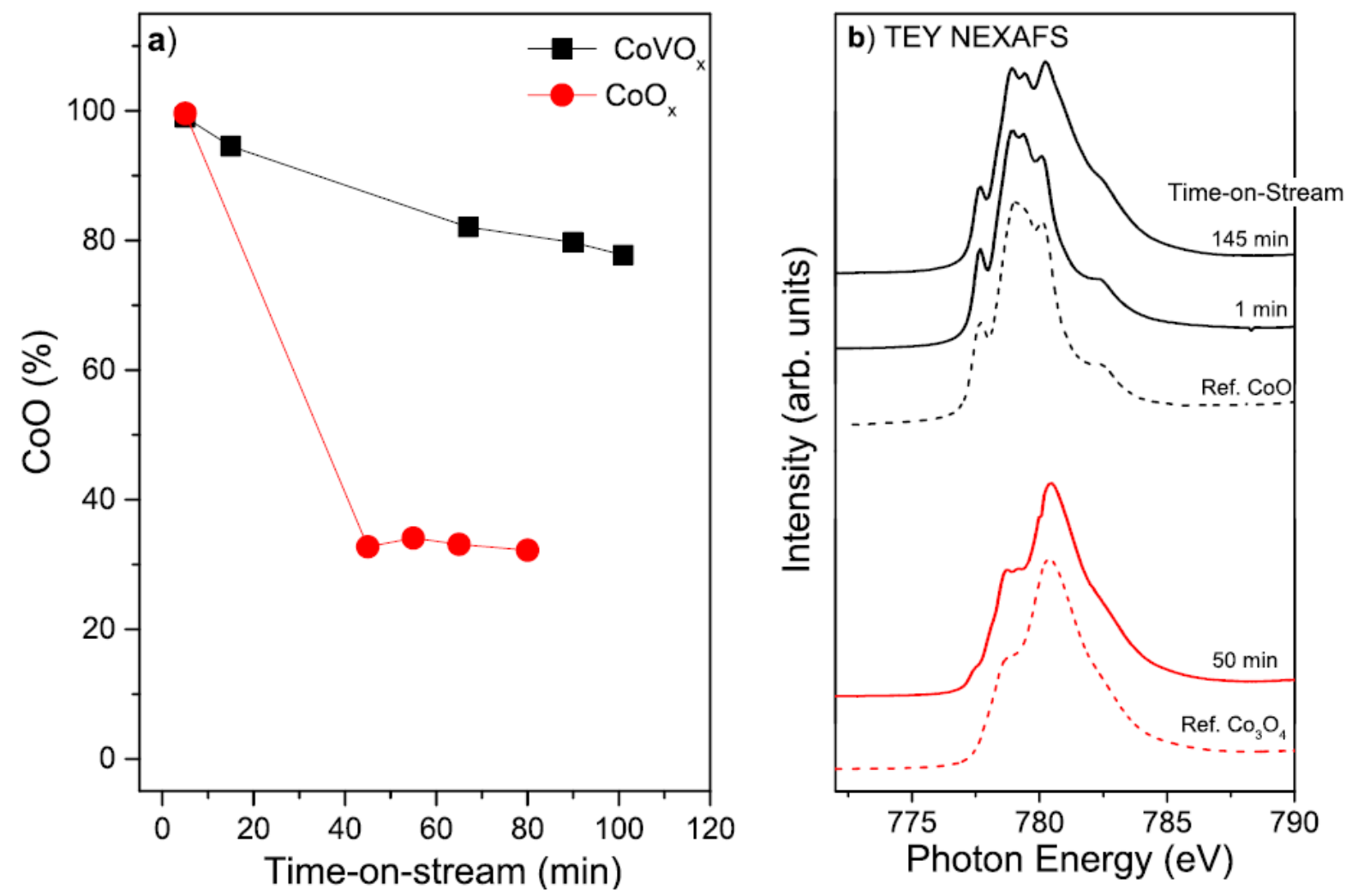

Figure 6. (a) $\% \mathrm{CoO}$ in the overall $\mathrm{CoO}$ and $\mathrm{Co}_{3} \mathrm{O}_{4}$ oxide layer quantified from NAP-XPS Co $2 p$ peak deconvolution as a function of time on stream. (b) Characteristic Co L3-edge NEXAFS spectra recorded at various steps in the COPrOx reaction. The spectra of reference $\mathrm{CoO}$ and $\mathrm{Co}_{3} \mathrm{O}_{4}$ oxides are included for comparison. The spectra for both $\mathrm{CoO}_{\mathrm{x}}$ and $\mathrm{CoVO}_{\mathrm{x}}$ catalysts were recorded at $250{ }^{\circ} \mathrm{C}$ in $1 \% \mathrm{CO}, 1 \% \mathrm{O}_{2}$, and $50 \% \mathrm{H}_{2}$ in $\mathrm{He}$, at $0.5 \mathrm{mbar}$ total pressure.

Short-term stability tests were performed at $250{ }^{\circ} \mathrm{C}$ in order to explicate the considerable differences in the durability of the two catalysts found in Figure 1c. The evolution of the \% $\mathrm{CoO}$, derived by deconvolution of Co $2 p$ peaks, as a function of the time on stream is shown in Figure 6a. Initially, the surface of both catalysts was dominated by $\mathrm{Co}^{2+}$, which decreases with time in favor of $\mathrm{Co}^{2.67+}$ formation. However, significant differences can be observed in the $\%$ fraction of $\mathrm{Co}^{2+}$ between the two samples. In particular, for $\mathrm{CoO}_{\mathrm{x}}$, the amount of $\mathrm{Co}^{2+}$ species rapidly drops to $30 \%$ due to $\mathrm{Co}^{2.67+}$ formation, while for $\mathrm{CoVO}_{\mathrm{x}}$, this value falls only up to $78 \%$ in the time scale of the experiment. Depth-dependent measurements of the Co $2 p$ peak were used to distinguish the distribution of the two oxides on the $\mathrm{CoVO}_{\mathrm{x}}$ surface (the information depth varied between 1.6 and $4.7 \mathrm{~nm}$ ). As shown in Figure S9, there is no evident 
depth dependency between the two Co $2 \mathrm{p}$ components, which indicates that $\mathrm{Co}^{2+}$ and $\mathrm{Co}^{2.67+}$ phases do not overlap significantly but are arranged separately on the $\mathrm{CoVO}_{\mathrm{x}}$ surface. Comparison of the Co L3-edges in Figure $6 \mathrm{~b}$ confirms the significant differences in the oxidation state of the two catalysts consistently with NAP-XPS. Overall, from the above presented results, it becomes clear that the thermal stability of octahedral $\mathrm{Co}^{2+}$ species in $\mathrm{COPrOx}$ conditions is improved by $\mathrm{V}$ addition.

3.3.2. The Oxidation State and Surface Distribution of Vanadium. To better understand the behavior of the $\mathrm{CoVO}_{\mathrm{x}}$ catalyst, it is important to determine the oxidation state and the stability of vanadium. Figure 7a depicts V 2p operando NAP-XPS spectra of $\mathrm{CoVO}_{x}$ at the initial and highest reaction temperatures. A complete list of the spectra for all temperatures can be found in Figure S10a. Vanadium may occur in several oxidation states that can be distinguished in photoemission experiments. As shown in Figure $7 \mathrm{a}$, at $50{ }^{\circ} \mathrm{C}$, the $\mathrm{V} 2 \mathrm{p}_{3 / 2}$ peak is deconvoluted in two components at 515.8 and $517.1 \mathrm{eV}$ corresponding to $\mathrm{V}^{4+}$ and $\mathrm{V}^{5+}$ species, respectively, $86-89$ while at $350{ }^{\circ} \mathrm{C}$, the $\mathrm{V}^{5+}$ peak dominates the spectrum at the expense of the $\mathrm{V}^{4+}$ component. Depth-dependent V 2p measurements (not shown) suggested that both vanadium oxidation states co-exist on the surface without evident depth distribution. From the analysis of $\% \mathrm{~V}$ in different oxidation states with reaction temperature (Figure $7 \mathrm{~b}$ ), we observe progressive oxidation of $\mathrm{V}^{4+}$ to $\mathrm{V}^{5+}$. The $\% \mathrm{Co}^{2+}$ included in the same graph is practically stable between 100 and $250{ }^{\circ} \mathrm{C}$, suggesting that the oxidation behavior of the two elements present in $\mathrm{CoVO}_{\mathrm{x}}$ is different. This is also supported by the stability experiments, where, after about $30 \mathrm{~min}$ on stream, all vanadium was converted to $\mathrm{V}^{5+}$ and remained stable onward (Figure 7a).
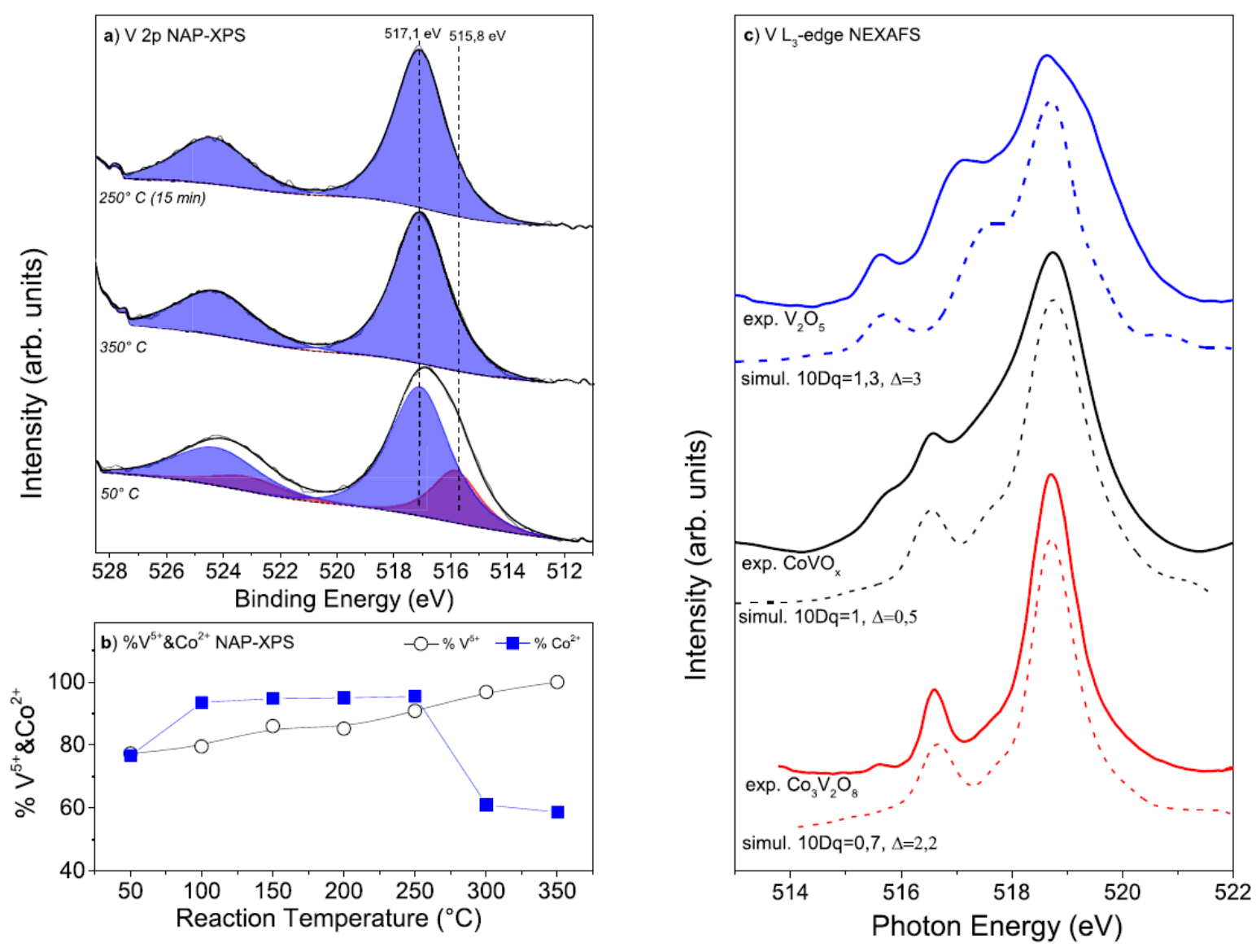
Figure 7. (a) Operando NAP-XPS V 2p spectra of the $\mathrm{CoVO}_{\mathrm{x}}$ catalyst recorded during temperature-dependent and stability COPrOx tests. The spectra are normalized to the same intensity and offset to the y axis. (b) $\%$ evolution of $\mathrm{V}^{5+}$ and $\mathrm{Co}^{2+}$ species with temperature calculated based on V $2 p$ peak deconvolution shown in (a) and Co $2 p$ spectra shown in Figure 5b. (c) Operando V L3-edge NEXAFS spectra of the $\mathrm{CoVO}_{\mathrm{x}}$ catalyst (solid black line) recorded at $250{ }^{\circ} \mathrm{C}$ during stability COPrOx tests. Reference $\mathrm{V} \mathrm{L} 3$-edge spectra of $\mathrm{V}_{2} \mathrm{O}_{5}$ and $\mathrm{Co}_{3} \mathrm{~V}_{2} \mathrm{O}_{8}$ (solid blue and red lines, respectively) are included for comparison. Theoretically simulated V L3-edges (dashed lines) for the same V oxidation state (5+) but different crystal field geometries ( $\mathrm{Td}$ and $\mathrm{Oh}$ ); $10 \mathrm{Dq}$ and $\Delta$ values adopted in the simulations are included under each theoretical spectrum. The exp. $\mathrm{Co}_{3} \mathrm{~V}_{2} \mathrm{O}_{8} \mathrm{~V}$ L3-edge spectrum is adapted with permission from ref 54. The exp. $\mathrm{V}_{2} \mathrm{O}_{5}$ spectrum is taken from ref 91 published by the PCCP Owner Societies.

In Figure 7c, the $\mathrm{V} \mathrm{L3}$-edge of $\mathrm{CoVO}_{\mathrm{x}}$ recorded at $250{ }^{\circ} \mathrm{C}$ during $\mathrm{COPrOx}$ stability tests is compared with spectra of $\mathrm{Co}_{3} \mathrm{~V}_{2} \mathrm{O}_{8}$ and $\mathrm{V}_{2} \mathrm{O}_{5}$ reference compounds. The evolution of V L3edges as a function of the reaction temperature is given in Figure S10b. The reference oxides were selected because of different vanadium coordination geometries with the oxygen ligands: tetrahedral (Td) for $\mathrm{Co}_{3} \mathrm{~V}_{2} \mathrm{O}_{8}{ }^{54}$ and distorted octahedral $(\mathrm{Oh})$ for $\mathrm{V}_{2} \mathrm{O}_{5},{ }^{55,90}$ albeit they are both composed of $\mathrm{V}^{5+}$ cations similar to $\mathrm{CoVO}_{\mathrm{x}}$. According to the literature, the various $\mathrm{V}$ oxidation states are differentiated by a shift in all discernible spectral features of $\mathrm{V}$ L-edge spectra. For example, the NEXAFS peak maximum of $\mathrm{V}^{5+}$ in $\mathrm{V}_{2} \mathrm{O}_{5}$ oxide is centered at around $518.8 \mathrm{eV}$ and is shifted by approximately $1 \mathrm{eV}$ from that of $\mathrm{V}^{4+} \cdot 36,77,91-94$ The alignment of the peak maximum for all NEXAFS spectra in Figure 7c confirms the XPS results, which show that $\mathrm{V}^{5+}$ is the dominant oxidation state of vanadium during COPrOx. The $\mathrm{CoVO}_{\mathrm{x}}$ peak profile does not contain the features around 517 and $519.5 \mathrm{eV}$, resembling more to the $\mathrm{Co}_{3} \mathrm{~V}_{2} \mathrm{O}_{8}$ than $\mathrm{V}_{2} \mathrm{O}_{5}$ reference oxide. This suggests that the majority of $\mathrm{V}^{5+}$ in our catalyst is mostly in $\mathrm{Td}$ coordination with $\mathrm{O}^{2-}$ anions and not as segregated $\mathrm{V}_{2} \mathrm{O}_{5}$ particles. However, there are some clear differences in the NEXAFS lineshapes between CoVOx and $\mathrm{Co}_{3} \mathrm{~V}_{2} \mathrm{O}_{8}$, with the most prominent being the increased intensity of the former at around 517.5 $\mathrm{eV}$. This cannot be induced by lower vanadium oxidation states since these states should have been also visible in the V $2 p$ spectra, supporting the idea of a distorted $\mathrm{V}-\mathrm{O}$ symmetry as compared to the vanadate reference oxide.

The spectral shape of the NEXAFS V L3-edge is strongly correlated to the coordination environment and the number of $3 \mathrm{~d}$ electrons of the metal center.51 Therefore, it may be used to provide interesting insights into the local geometry around the $\mathrm{V}^{5+}$ cation, ${ }^{92}$ as has been shown previously for other transition metal oxides. ${ }^{95,96}$ Theoretical simulation of the V L3edge using the charge-transfer multiplet (CTM) approach can help to estimate the variations in the $\mathrm{V}-\mathrm{O}$ interaction that are accountable for the differences in the lineshapes. ${ }^{51,52}$ The two key parameters affecting the shape of the calculated XAS curves are 10Dq (crystal field splitting) and $\Delta$ (charge transfer energy). The 10Dq parameter determines the splitting in the crystal field and depends mainly on the metal-ligand distance, in a way that an increase in the value of $10 \mathrm{Dq}$ corresponds to a decrease in $\mathrm{V}-\mathrm{O}$ distance. The charge transfer energy term $\Delta$ describes the interaction of V $2 p$ ions with delocalized electrons from the $\mathrm{O} 2 \mathrm{p}$ orbital. ${ }^{31} \mathrm{An}$ increase in $\Delta$ value corresponds to weaker interaction between $\mathrm{V} 2 \mathrm{p}$ and $\mathrm{O} 2 \mathrm{p}$ orbitals. The theoretically simulated V L3-edges that give the best accordance with the experimental spectra are included in Figure $7 \mathrm{c}$, while the $10 \mathrm{Dq}$ and $\Delta$ parameters are shown in Table 2 . The $\mathrm{CoVO}_{\mathrm{x}}$ catalyst has higher $10 \mathrm{Dq}$ and lower $\Delta$ values as compared to $\mathrm{Co}_{3} \mathrm{~V}_{2} \mathrm{O}_{8}$. According to the assignment mentioned above, the distance between $\mathrm{V}$ and $\mathrm{O}$ ions is shorter and their interaction is stronger in $\mathrm{CoVO}_{\mathrm{x}}$ as compared to $\mathrm{Co}_{3} \mathrm{~V}_{2} \mathrm{O}_{8}$. Assuming that $\mathrm{Co}$ and $\mathrm{V}$ ions share 
some oxygen atoms in their lattice, shorter $\mathrm{V}-\mathrm{O}$ bonds induce correspondingly longer $\mathrm{Co}^{-} \mathrm{O}$ bonds. The net result of this change is that the cobalt $3 \mathrm{~d}$ electrons are more localized on the cobalt atoms in $\mathrm{CoVO}_{\mathrm{x}}$ as compared to $\mathrm{Co}_{3} \mathrm{~V}_{2} \mathrm{O}_{8}$ bulk oxide. ${ }^{85}$

The surface atomic percent (at. \%) of $\mathrm{V}$ on the $\mathrm{CoVO}_{\mathrm{x}}$ surface was determined from the $\mathrm{V} 2 \mathrm{p}$ and Co $2 p$ NAP-XPS peaks. In order to estimate the distribution of vanadium in the outer surface layers, the $\% \mathrm{~V}$ concentration was calculated at different analysis depths using Co $2 \mathrm{p}$ and V $2 p$ peaks recorded with increasing photon energies. ${ }^{97}$ The results presented in Figure $\mathrm{S} 11$ show that the $\mathrm{V}$ concentration decreases with the analysis depth. This indicates that $\mathrm{V}$ and $\mathrm{Co}$ are not homogeneously mixed in the outermost $5 \mathrm{~nm}$ of the catalyst (maximum analysis depth of NAP-XPS) but form a layer structure where $\mathrm{V}$ is the shell and $\mathrm{CoO}$ is the inner core. More details will be provided based on quantitative simulation of these results shown below.

Table 2. Symmetry, 10Dq (Crystal Field Splitting), and $\Delta$ (Charge Transfer Energy) Parameters Found by the Multiplet Calculation to Give the Best Accordance with the Experimental Spectra Shown in Figure 7c

\begin{tabular}{lccc} 
& symmetry & $10 \mathrm{Dq}(\mathrm{eV})$ & $\Delta(\mathrm{eV})$ \\
$\mathrm{V}_{2} \mathrm{O}_{5}$ & $O_{h}$ & 1.3 & 3 \\
$\mathrm{Co}_{3} \mathrm{~V}_{2} \mathrm{O}_{8}$ & $T_{d}$ & 0.7 & 2.2 \\
$\mathrm{CoVO}_{x}$ & $T_{d}$ & 1 & 0.5 \\
\hline
\end{tabular}

3.3.3. Evolution of the Adsorbed Species during COPrOx. Operando NAP-XPS provides the necessary chemical and surface specificity to identify adsorbed carbon species during the reaction. In Figure 8, the $\mathrm{C} 1 \mathrm{~s}$ spectra at characteristic reaction temperatures are shown together with the evolution of the carbon surface concentration for $\mathrm{CoO}_{\mathrm{x}}$ and $\mathrm{CoVO}_{\mathrm{x}}$ catalysts. The amount of adsorbed carbon over $\mathrm{CoVO}_{\mathrm{x}}$ is constant up to $200{ }^{\circ} \mathrm{C}$, while above this temperature, it shows a decreasing tendency. Carbon evolution over $\mathrm{CoO}_{\mathrm{x}}$ is notably different, exhibiting a fast decrease of carbon population up to $200{ }^{\circ} \mathrm{C}$ and a steep rising above this temperature, which overwhelms almost four times the carbon observed on $\mathrm{CoVO}_{\mathrm{x}}$.

Deconvolution of the $\mathrm{C}$ 1s peak can help to distinguish the nature of adsorbed carbon. As shown in Figure 8, four main carbon species coexist on the two surfaces. Based on previous reports, the peak at $284.5 \mathrm{eV}$ is due to $\mathrm{C}-\mathrm{H}$ and $\mathrm{C}-\mathrm{C}$ bonds, while the two peaks at 286.4 and $288.4 \mathrm{eV}$ are attributed to oxygenated carbon species like $\mathrm{C}-\mathrm{O}-\mathrm{C}$ and $\mathrm{O}-\mathrm{C}=\mathrm{O}$, respectively. ${ }^{23}$ These species persist on the surface of $\mathrm{CoVO}_{\mathrm{x}}$ catalysts at all reaction temperatures with small variations in their relative population. In the case of $\mathrm{CoO}_{x}$, the evolution of carbon species is remarkably different, with a new $\mathrm{C} 1 \mathrm{~s}$ peak at 289.3 dominating the surface above $250{ }^{\circ} \mathrm{C}$. The binding energy of this peak is characteristic for carbonate $\left(\mathrm{CO}_{3}{ }^{2-}\right)$ or oxalate $\left((\mathrm{COO})^{2-}\right)$ species as has been clearly shown previously. ${ }^{98,99}$

This attribution is confirmed by the $\mathrm{O} 1 \mathrm{~s}$ spectra recorded at $350{ }^{\circ} \mathrm{C}$ and shown in Figure $8 \mathrm{~b}$. The overall $\mathrm{O} 1 \mathrm{~s}$ peak can be deconvoluted in two main oxygen species. The one around $529.6 \mathrm{eV}$ is assigned to the lattice oxygen of the cobalt and vanadium oxides $\left(\mathrm{CoO}, \mathrm{Co}_{3} \mathrm{O}_{4}\right.$, and $\mathrm{VO}_{\mathrm{x}}$ have very similar $\mathrm{O} 1 \mathrm{~s}$ binding energies). ${ }^{23,100}$ The high binding energy components are located at $531 \mathrm{eV}\left(\mathrm{CoVO}_{\mathrm{x}}\right)$ and $531.9 \mathrm{eV}\left(\mathrm{CoO}_{\mathrm{x}}\right)$ and can be attributed to oxygenated 
carbon/hydroxyl species ${ }^{101,102}$ and carbonate/oxalate species, ${ }^{98,99}$ respectively. Kruse and coworkers showed that the binding energy difference between the $\mathrm{O} 1 \mathrm{~s}$ and $\mathrm{C} 1 \mathrm{~s}$ peaks $\triangle \mathrm{BE}(\mathrm{O} 1 \mathrm{~s}-\mathrm{C} 1 \mathrm{~s})$ can be used to distinguish between carbonate and oxalate carbon species. Taking as an internal reference the position of the $\mathrm{C}-\mathrm{C}$ peak, this difference is found in our case to be $242.1 \pm 0.1 \mathrm{eV}$, which is in good agreement with the value of $242.0 \pm 0.2 \mathrm{eV}$ reported for carbonate species. ${ }^{98,99}$
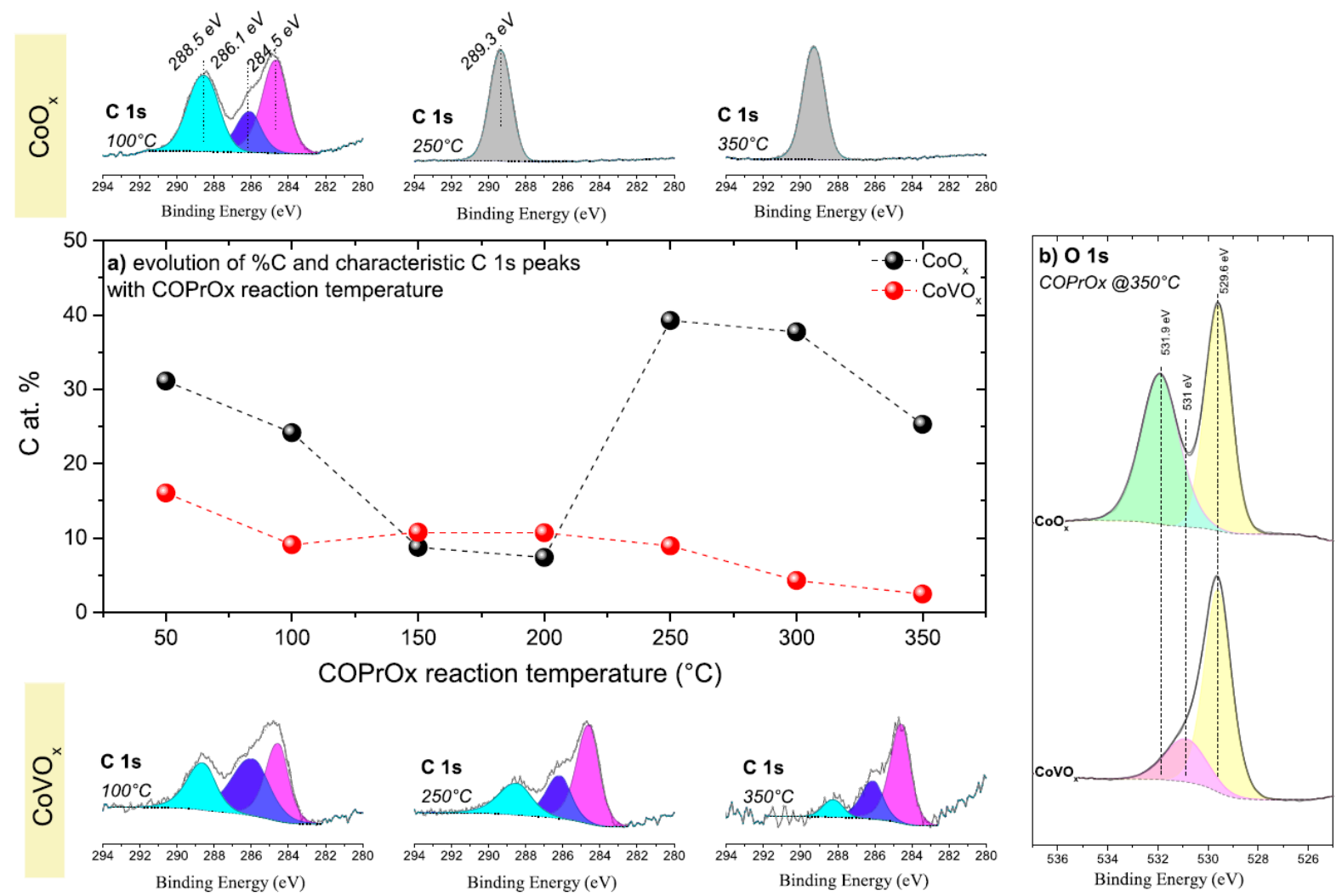

Figure 8. (a) Operando $\mathrm{C}$ 1s NAP-XPS spectra recorded at different COPrOx reaction temperatures over $\mathrm{CoO}_{\mathrm{x}}$ (top) and $\mathrm{CoVO}_{\mathrm{x}}$ catalysts. The middle graph shows the evolution of the carbon atomic percent (at. \%) at the surface $(2 \mathrm{~nm})$ as a function of the COPrOx reaction temperature, calculated by the $\mathrm{C} 1 \mathrm{~s}$, Co $2 \mathrm{p}$, and V $2 \mathrm{p}$ peaks. (b) Comparison of the O 1s NAPXPS spectra of the two catalysts recorded at $350{ }^{\circ} \mathrm{C}$ in $\mathrm{COPrOx}$. The $\mathrm{O} 1 \mathrm{~s}$ peaks are normalized to the same intensity and offset to the $\mathrm{y}$ axis.

Carbonates have been proposed both as spectators ${ }^{103}$ and inhibitors ${ }^{23}$ for the $\mathrm{CO}$ oxidation reaction over cobalt surfaces. This ambiguity is probably related to the specific reaction conditions and/or the chemical nature of carbonate species. Indeed, the absence of $\mathrm{H}_{2}$ from the reaction mixture in ref 103 is expected to decrease the amount and stability or carbonates as compared to the present study. In addition, an evident difference in the nature of the carbonates between ref 103 and this work is manifested by the considerable shift in the $\mathrm{C} 1 \mathrm{~s}$ binding energy (288.2 eV in ref 103, instead of $289.3 \mathrm{eV}$ here). In our recent work, ${ }^{23}$ the differences in the reactivity between $\mathrm{CoO}$ and $\mathrm{Co}_{3} \mathrm{O}_{4}$ were attributed to their different capacity to form carbonates under COPrOx reaction conditions. The NAP-XPS analysis evidences that stabilization of the $\mathrm{Co}^{2+}$ oxidation state by the $\mathrm{V}$ promoter controls the amount of adsorbed carbonates during the reaction, having direct benefits on the reactivity. 
3.4. Reducibility of CoVOx Measured by In Situ NEXAFS at 1 bar. The operando NAPXPS and NEXAFS results clearly demonstrated that $\mathrm{Co}^{2+}$ remains the dominant cobalt oxidation state during $\mathrm{COPrOx}$ over $\mathrm{CoVO}_{\mathrm{x}}$, in contrast to the pure $\mathrm{CoO}_{\mathrm{x}}$ catalyst, which forms a mixture of $\mathrm{Co}^{3+}, \mathrm{Co}^{2+}$, and $\mathrm{Co}^{0}$, at least above $200{ }^{\circ} \mathrm{C}$. This finding provides clear evidence that the high catalytic activity and stability of $\mathrm{CoVO}_{\mathrm{x}}$ demonstrated in the catalytic tests (Figure 1) is related to the enhanced redox stability of $\mathrm{Co}^{2+}$ states. However, before being able to directly correlate NAP-XPS with fix-bed reactor results, the effect of the pressure gap between the two experiments $(0.1$ mbar in NAP-XPS vs of 1 bar in catalytic tests) should be considered. The XRD analysis of the spent catalysts showed that their bulk structure was not notably affected by the COPrOx reaction, which contradicts the fast adjustment of the surface oxidation state and composition found in NAP-XPS. Therefore, in order to fulfill the requirements of surface sensitivity and atmospheric pressure operation, a recently developed experimental approach was selected, which allows performing in situ NEXAFS under a controlled gas atmosphere at 1 bar. ${ }^{56}$ Due to technical restrictions, these experiments could not be performed in the COPrOx mixture; therefore, the stability of $\mathrm{CoVO}_{\mathrm{x}}$ was investigated under a 1 bar $\mathrm{H}_{2}$ atmosphere (without $\mathrm{CO}$ and $\mathrm{O}_{2}$ addition) and $10 \% \mathrm{O}_{2} / \mathrm{He}$, which are much harsher reducing and oxidizing conditions, respectively, than those the catalyst faces in the COPrOx reaction.
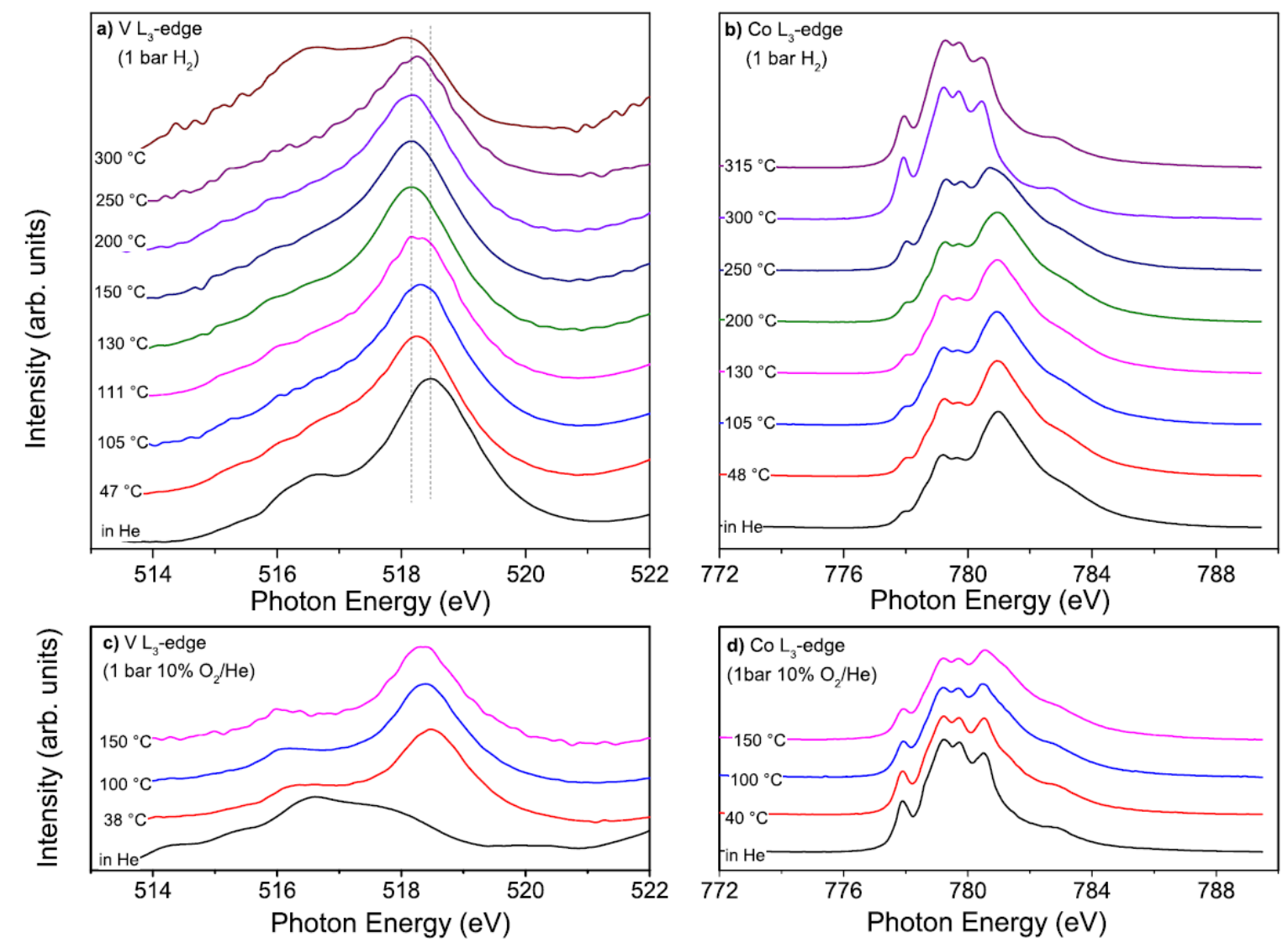

Figure 9. (a) In situ V L3-edge and (b) Co L3-edge NEXAFS spectra of CoVOx catalysts recorded at 1 bar $\mathrm{H}_{2}$ between 47 and $315^{\circ} \mathrm{C}$. (c) In situ V L3-edge and (d) Co L3-edge NEXAFS spectra of $\mathrm{CoVO}_{x}$ catalysts recorded at 1 bar $10 \% \mathrm{O}_{2}$ in He between 38 and $150{ }^{\circ} \mathrm{C}$. All spectra are normalized to the same intensity and offset to the y axis.

Figure 9a and Figure 9b show the $\mathrm{V}$ and Co L3-edges, respectively, of pristine (calcined) $\mathrm{CoVO}_{\mathrm{x}}$ upon annealing in $\mathrm{H}_{2}$. Not surprisingly, just after calcination, the $\mathrm{V}$ and Co L3- edges 
correspond to $\mathrm{V}^{5+}$ and a mixture of $\mathrm{Co}^{3+}$ and $\mathrm{Co}^{2+}$ species, respectively. Annealing in $\mathrm{H} 2$ partially reduces both $\mathrm{V}$ and $\mathrm{Co}$, but not at the same temperature. $\mathrm{V}^{5+}$ readily reduces at least partially to $\mathrm{V}^{4+}$ already from $50{ }^{\circ} \mathrm{C}$, and after this temperature, the spectral shape remains similar up to $250{ }^{\circ} \mathrm{C}$. Only at $300{ }^{\circ} \mathrm{C}$, spectral modifications consistent with further partial reduction to $\mathrm{V}^{3+}$ are observed, through the appearance of a distinct peak at ca. $516.5 \mathrm{eV}$. In the case of cobalt, the reduction of $\mathrm{Co}^{3+}$ appears above $200{ }^{\circ} \mathrm{C}$, while at $315^{\circ} \mathrm{C}$, the lineshape of Co L3-edge resembles that of $\mathrm{Co}^{2+}$.

The oxidation behavior between vanadium and cobalt in $10 \% \mathrm{O}_{2}$ in $\mathrm{He}$ at 1 bar (Figure $9 \mathrm{c}, \mathrm{d}$ ) is also very different. When the pre-reduced catalyst is exposed to $\mathrm{O}_{2}$, vanadium is readily oxidized to the $\mathrm{V}^{5+}$ state already at $38^{\circ} \mathrm{C}$ and remains stable afterwards, while cobalt is much more resistant to oxidation. At the maximum annealing temperature of this experiment (150 ${ }^{\circ} \mathrm{C}$ ), only a part of $\mathrm{Co}^{2+}$ has been oxidized to $\mathrm{Co}^{3+}$ as deduced by the Co L3-edge lineshape. Please note that, in $10 \% \mathrm{O}_{2}$ in $\mathrm{He}$, cobalt is more oxidized as compared to the COPrOx mixture shown in NAP-XPS, which is however expected due to the much higher oxidative effect of a $10 \% \mathrm{O}_{2}$ atmosphere. However, this result clearly shows that cobalt and vanadium do not respond to the same manner in redox environments with the former being much more resistant to oxidation than the latter. Consequently, in situ NEXAFS confirms that the $\mathrm{Co}^{2+}$ state might be stable under atmospheric pressure conditions that closely resemble those of the catalytic tests. This is further evidence that the higher activity and stability of $\mathrm{CoVO}_{\mathrm{x}}$ should be a direct consequence of the redox stability of surface $\mathrm{Co}^{2+}$ species.

\section{DISCUSSION}

4.1. Surface Arrangement. The analysis of the photoemission, X-ray adsorption, and STEM results evokes that the vast majority of vanadium resides over cobalt particles, and this influences the electronic structure of the two materials. Two possible arrangements can be correlated with these experimental findings: (i) formation of well-dispersed two-dimensional $\mathrm{VO}_{\mathrm{x}}$ overlayer over the $\mathrm{CoO}$ support (i.e., $\mathrm{VO}_{\mathrm{x}} @ \mathrm{CoO}$ ) or (ii) the two materials intermix at their interface forming a thin cobalt-vanadium mixed oxide layer (i.e., $\mathrm{Co}_{\mathrm{x}} \mathrm{V}_{\mathrm{y}} \mathrm{O}_{\mathrm{z}}$ ). The analysis of $\mathrm{V}$ L-edge presented above suggests that the $\mathrm{V}^{5+}$ species on $\mathrm{CoVO}_{\mathrm{x}}$ catalysts are not octahedrally coordinated as expected for $\mathrm{V}_{2} \mathrm{O}_{5}$ bulk oxide, but tetrahedrally. However, the shape and position of the photoemission and absorption spectra of $\mathrm{CoVO}_{\mathrm{x}}$ do not exactly match neither with twodimensional vanadium oxides ${ }^{91,104}$ nor with octahedral cobalt vanadate compounds (e.g., $\left.\mathrm{Co}_{3} \mathrm{~V}_{2} \mathrm{O}_{8}\right)^{54,85,91,104}$ and therefore do not allow a direct and unambiguous identification of the arrangement at the interface in our case.

Theoretical simulation of the photoelectron peak intensities was used in order to decide which of the above described arrangements fits better with the experimental data. Figure 10 presents the $\% \mathrm{~V}$ at the surface as a function of the analysis depth calculated based on theoretically simulated Co $2 p$ and V $2 p$ photoemission spectra using SESSA version 2.1.1 software. Three different arrangement models were used for the simulations, assuming a $\mathrm{V}$-containing oxide layer over a $\mathrm{CoO}$ core: (i) $\mathrm{V}_{2} \mathrm{O}_{5} @ \mathrm{CoO}$, (ii) $\mathrm{Co}_{3} \mathrm{~V}_{2} \mathrm{O}_{8} @ \mathrm{CoO}$, and (iii) $\mathrm{Co}_{6} \mathrm{~V}_{2} \mathrm{O}_{11} @ \mathrm{CoO}$. In all cases, the sample morphology was $50 \mathrm{~nm}$ diameter layered spheres with $\mathrm{CoO}$ in the inner core and an overlayer of $\mathrm{V}_{2} \mathrm{O}_{5}, \mathrm{Co}_{3} \mathrm{~V}_{2} \mathrm{O}_{8}$, or $\mathrm{Co}_{6} \mathrm{~V}_{2} \mathrm{O}_{11}$. The thickness of the overlayer was adjusted in order to fit the experimental $\% \mathrm{~V}$ at the $230 \mathrm{eV} \mathrm{KE}$ (dashed line) measurement. After finding this value, the arrangement model was kept identical in the calculations of the other two depths. 


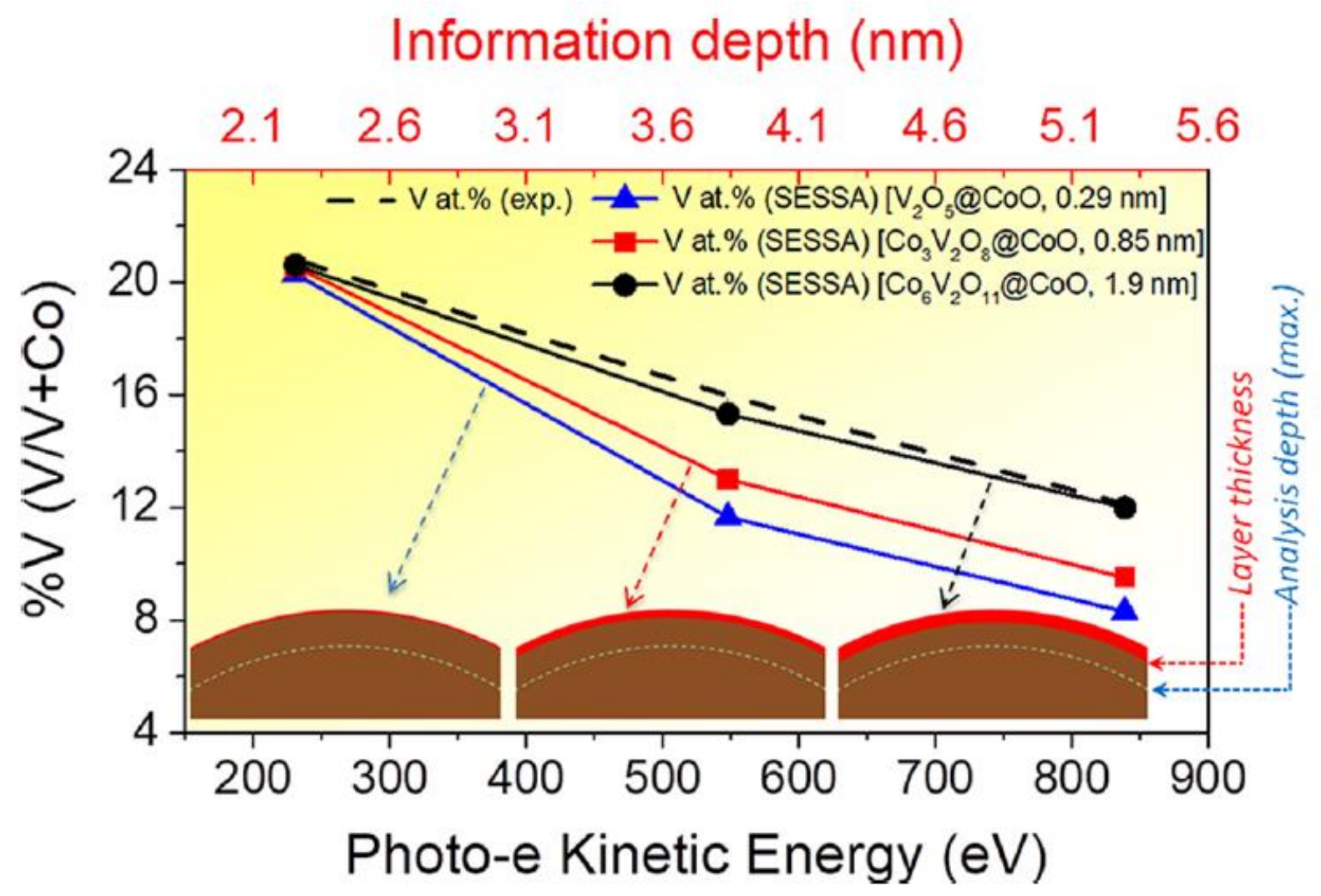

Figure 10. Surface $\%$ at. $V$ as a function of the photoelectron kinetic energy (or information depth) calculated based on theoretically simulated Co $2 \mathrm{p}$ to V $2 \mathrm{p}$ spectra using SESSA version 2.1.1 software. Three different arrangement configurations were used in the calculations (see figure annotation). A schematic representation of the layer thickness obtained for each model is included in the figure. The black dashed line indicates the experimental \% at. V obtained by NAP-XPS, and results are shown in Figure S11.

From Figure 10, it is clear that the $\mathrm{V}_{2} \mathrm{O}_{5} / \mathrm{CoO}$ arrangement has the highest deviation from the experimental results. In addition, the calculated thickness of the $\mathrm{V}_{2} \mathrm{O}_{5}$ layer $(0.29 \mathrm{~nm})$ corresponds to an overall 1.1 at.\%V (calculated based on the volume of the particles assumed in the simulation), which is far less than the nominal 12.5 at.\%V loading. On the other hand, mixed cobalt-vanadate layers can better simulate the experimental results and provide more realistic at. $\% \mathrm{~V}$. The best fitting was found by a hypothetical cobalt-vanadate layer rich in cobalt $\left(\mathrm{Co}_{6} \mathrm{~V}_{2} \mathrm{O}_{11}\right)$ with $1.9 \mathrm{~nm}$ in thickness, which corresponds to an 8 at.\% overall $\mathrm{V}$ loading. Therefore, based on the quantitative simulation of the depth profile data, the mixed cobalt-vanadate layer on the surface of $\mathrm{CoO}$ is proposed as the most likely surface arrangement of the $\mathrm{CoVO}_{\mathrm{x}}$ catalyst under reaction conditions. Taking into account that metallic Co was detected in the XRD (Figure S4), a complex structure consisting of cobalt-vanadate on the surface and metallic cobalt in the bulk should be anticipated as the active state of the $\mathrm{CoVO}_{\mathrm{x}}$ catalyst.

4.2. Effect of the V Promoter on the Reactivity of Co Ions. Catalytic tests show that vanadium addition to cobalt oxide results in a material with a higher $\mathrm{CO}$ conversion in the COPrOx reaction. There are two general paths in which promoters, $\mathrm{V}$ in our case, may influence the reactivity of the active Co phase. The first is related to an electronic modification of the catalytic active sites and the second to structural stabilization that enhances their abundance during the reaction. ${ }^{105}$ Our results show that the population of $\mathrm{Co}^{2+}$ 
on the surface of bulk metallic cobalt is a strong function of the working conditions. This fact does not change with $\mathrm{V}$ addition, but under identical conditions, $\mathrm{CoVO}_{\mathrm{x}}$ has systematically higher abundance of $\mathrm{Co}^{2+}$ as compared to $\mathrm{CoO}_{\mathrm{x}}$. Therefore, the primary effect of $\mathrm{V}$ on $\mathrm{Co}$ might be related to the structural stabilization of $\mathrm{Co}^{2+}$ sites and their resistance to $\mathrm{Co}^{3+}$ transformation. As we have shown previously, this affects the COPrOx reactivity since $\mathrm{Co}^{2+}$ surfaces are less susceptible to carbonate species formation, ${ }^{23}$ which is one of the main reasons for cobalt catalyst deactivation (see Figure 11).

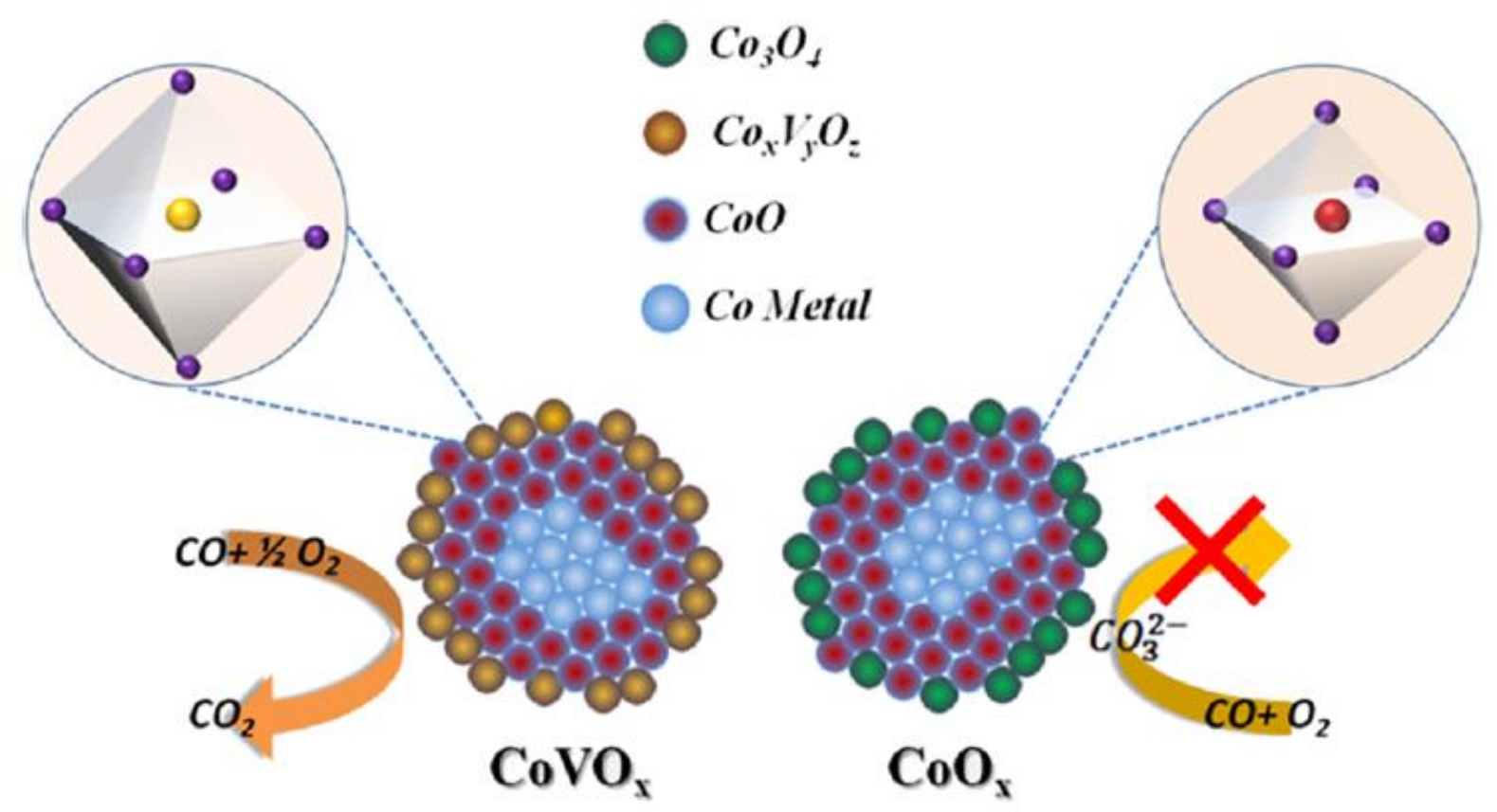

Figure 11. Schematic representation showing the proposed arrangement (cross section) of the various cobalt oxidation states over pure $\left(\mathrm{CoO}_{\mathrm{x}}\right)$ and $\mathrm{V}$-modified $\left(\mathrm{CoVO}_{\mathrm{x}}\right)$ cobalt nanopowder catalysts in the COPrOx reaction. The difference in the bond distance between the central $\mathrm{Co}^{2+}$ (red or dark yellow spheres) and the corner $\mathrm{O}^{2-}$ ions (purple spheres) in the $\mathrm{Co}-\mathrm{O}$ octahedron is also illustrated.

To elucidate the stabilization effect of $\mathrm{V}$ on $\mathrm{Co}^{2+}$, we first need to consider the mechanism of $\mathrm{CoO}$ oxidation to $\mathrm{Co}_{3} \mathrm{O}_{4}$. Combining theory with experiment, Robinson and coworkers 106 showed that $\mathrm{CoO}$ oxidation proceeds by $\mathrm{Co}^{2+}$ ion diffusion to the outer surface through the oxide lattice and/or the grain boundaries. In this process, the $\mathrm{O}$ lattice is not considerably affected and it is expected to remain rigid.106 Our study provides evidences that $\mathrm{Co}^{2+}$ and $\mathrm{V}^{5+}$ ions at the $\mathrm{CoVO}_{\mathrm{x}}$ surface share, to a large extent, the same lattice oxygen forming a mixed oxide (referred as $\mathrm{Co}_{\mathrm{x}} \mathrm{V}_{\mathrm{y}} \mathrm{O}_{\mathrm{z}}$ ). The vanadium ions can change between $4+$ and $5+$ valences more easily than cobalt changes between the $2+$ and $3+$ ones, as demonstrated in NAP-XPS and the atmospheric pressure NEXFAS experiments. Therefore, since $\mathrm{V}$ has higher redox ability as compared to $\mathrm{Co}$, it will be selectively oxidized by $\mathrm{O}_{2}$ gas acting as a buffer for $\mathrm{Co}^{2+}$ oxidation. In addition, $\mathrm{V}$ can undergo fast redox cycles by storing and releasing oxygen during a reaction cycle. Obviously, the rate of reduction and reoxidation cycles defines the ultimate vanadium oxidation state in reaction equilibrium. Taking into account that the COPrOx mixture contains only $1 \% \mathrm{O}_{2}$, this can slow down the kinetics of cobalt oxidation and increase the durability of the catalyst. Similarly, in reducing conditions, $\mathrm{V}^{5+}$ will be the first ion to release oxygen and convert to $\mathrm{V}^{4+}$, keeping $\mathrm{Co}^{2+}$ stable. An analogous stability mechanism has been previously proposed for the $\mathrm{Fe}$-doped $\mathrm{Co}_{3} \mathrm{O}_{4}$ catalyst. ${ }^{107}$ 
In addition to the clearly manifested stability of $\mathrm{Co}^{2+}$, the analysis of absorption spectra gave evidences of a less pronounced, but still distinguishable, difference between the two catalysts. Specifically, although $\mathrm{V}$ does not change the coordination symmetry of $\mathrm{Co}^{2+}$, it affects the $\mathrm{Co}^{2+}-\mathrm{O}$ anion distance in the $\mathrm{CoVO}_{\mathrm{x}}$ surface oxide lattice as well as the $\mathrm{Co}^{2+}$ electronic state. Unfortunately, it was not possible to quantify the electronic charge of cobalt ions in the two catalysts, but analysis of the spectroscopic results can qualitatively explain the electronic effects. As mentioned above, the $\mathrm{Co}^{2+}$ electronegativity in $\mathrm{CoVO}_{\mathrm{x}}$ is higher as compared to $\mathrm{CoO}_{\mathrm{x}}$, while the bond distance between $\mathrm{Co}^{2+}$ and $\mathrm{O}^{2-}$ increases (Figure 11). Theoretical models predict that a higher metal electronegativity should be followed by lower interaction with oxygen, thus weaker metal-oxygen bond. ${ }^{108}$ This can be related to enhanced oxygen mobility on the surface of the $\mathrm{CoVO}_{\mathrm{x}}$ catalyst. The oxidation of $\mathrm{CO}$ on cobalt oxide follows a Mars-van Krevelen mechanism, ${ }^{23}$ which implies that a higher mobility of lattice oxygen ions will result in higher reaction rates. ${ }^{109}$ This hypothesis is directly supported by the fact that $\mathrm{CoVO}_{\mathrm{x}}$ has higher activity in the $150-200{ }^{\circ} \mathrm{C}$ region (Figure 1), even if NAP-XPS analysis shows that the amount of adsorbed carbon species (Figure 8) is very similar in the two catalysts. Therefore, $\mathrm{V}$ addition has a dual function on cobalt, first it helps to stabilize the $\mathrm{Co}^{2+}$ phase and to inhibit the carbonate-induced deactivation and second it modifies the electronic state of $\mathrm{Co}^{2+}$, increasing the oxygen mobility and in this way enhancing the reaction kinetics.

One should not overlook the notable enhancement of the surface area caused by vanadium addition on cobalt. Definitely, this increase does not correspond to a proportional increase in the cobalt surface sites since, as shown, the cobalt surface is covered/mixed with vanadium species. However, apparently $\mathrm{V}$ promotion helps to maintain the morphology of $\mathrm{CoO}$ particles (Figure 2), most probably by limiting surface diffusion and agglomeration of cobalt aggregates. However, in contrast to the cobalt oxidation state, which shows a good correlation with the reactivity, the specific surface area differences between $\mathrm{CoO}_{\mathrm{x}}$ and $\mathrm{CoVO}_{\mathrm{x}}$ seem not to be so critical under the employed reaction conditions. A first argument supporting this idea comes from the strong deactivation of $\mathrm{CoO}_{x}$ observed in the time-of-stream experiments of Figure 1c. The surface area of the $\mathrm{CoO}_{\mathrm{x}}$ catalyst increases after the reaction (Table 1); therefore, the activity decrease observed after $20 \mathrm{~min}$ in Figure 1c cannot be due to loss of surface area and should be related to the changes in the cobalt oxidation state revealed by NAP-XPS and NEXAFS. In addition, in the light-off tests (Figure 1a) at $150{ }^{\circ} \mathrm{C}$, the CO conversion of the $\mathrm{CoVO}_{\mathrm{x}}$ catalyst is ca. $50 \%$ higher $\left(13.9\right.$ vs $8.6 \%$ for $\mathrm{CoO}_{\mathrm{x}}$ ), despite the fact that this catalyst has more than $700 \%$ higher specific surface area (Table 1). At low temperature and low conversion conditions, diffusion phenomena are not rate-limiting, and therefore the overall reaction rate is controlled by the intrinsic reaction kinetics. Consequently, the dominant role of the surface oxidation state of cobalt on the reactivity remains the most likely explanation of the catalytic results.

\section{CONCLUSIONS}

The COPrOx activity of cobalt oxide is significantly improved by introduction of vanadium. Several ex situ and operand methods were applied to understand the promotion effect including NAP-XPS and atmospheric NEXAFS at 1 bar. The bulk structure and morphology of V-modified catalysts is not significantly influenced as compared to pure cobalt. However, detailed spectroscopic analysis revealed the formation of a mixed cobalt-vanadate phase on the surface, which does not resemble the known bulk mixed oxides. This phase is formed by tetrahedrally coordinated $\mathrm{V}^{5+}$ and octahedral $\mathrm{Co}^{2+}$ species. Both electronic and structural effects must be considered to understand cobalt catalyst promotion by vanadium. In 
particular, $\mathrm{V}$ prevents the oxidation of $\mathrm{CoO}$ and provides stable active octahedral $\mathrm{Co}^{2+}$ sites for COPrOx, resistant to deactivation through carbonate species formation. In addition to that, we found evidences of modifications in the electronic state of $\mathrm{Co}^{2+}$ species induced by $\mathrm{V}$ promotion, in the direction that enhances the reaction kinetics. Furthermore, by using NEXAFS at atmospheric pressure, we could show that $\mathrm{Co}^{2+}$ species are preserved on the $\mathrm{CoVO}_{\mathrm{x}}$ surface at a temperature and pressure relevant to the catalytic tests. Overall, our study shows that one can use insights from operando surface spectroscopy to design and produce better COPrOx catalysts. Taking into account the rising accessibility and availability of these methods, this can be a sustainable strategy for the development of new-generation catalysts.

\section{- ASSOCIATED CONTENT}

\section{Supporting Information}

The Supporting Information is available free of charge at https://pubs.acs.org/doi/10.1021/acscatal.0c05482.

TPR- $\mathrm{H}_{2}$ of calcined $\mathrm{CoO}_{\mathrm{x}}$ and $\mathrm{CoVO}_{\mathrm{x}}$ catalysts; methane selectivity and catalytic performance of pure vanadium oxide after different pretreatments for COPrOx; ex situ XRD patterns of fresh, reduced, and spent $\mathrm{CoO}_{\mathrm{x}}$ and $\mathrm{CoVO}_{\mathrm{x}}$ catalysts; additional STEMEDS and HR-STEM images; characteristic examples of Co $2 p$ deconvolution; in situ NEXAFs spectra of Co L3-edge as a function of reaction temperature during COPrOx; NAP-XPS depthprofiling analysis of $\mathrm{Co} 2 \mathrm{p}$ over $\mathrm{CoO}_{\mathrm{x}}$ and $\mathrm{CoVO}_{\mathrm{x}}$ during $\mathrm{COPrOx}$; and the \%at. $\mathrm{V}$ as a function of the NAP-XPS analysis depth (PDF)

\section{- AUTHOR INFORMATION}

\section{Corresponding Author}

Spyridon Zafeiratos - Institut de Chimie et Procédés pour l'Energie, l'Environnement et la Santé (ICPEES), ECPM, UMR 7515 CNRS - Université de Strasbourg, 67087 Strasbourg, France; orcid.org/0000-0001-8165-2585; Email: spiros.zafeiratos@unistra.fr

\section{Authors}

Liping Zhong - Institut de Chimie et Procédés pour l'Energie, l'Environnement et la Santé (ICPEES), ECPM, UMR 7515 CNRS - Université de Strasbourg, 67087 Strasbourg, France Mathias Barreau - Institut de Chimie et Procédés pour

l'Energie, l'Environnement et la Santé (ICPEES), ECPM, UMR 7515 CNRS - Université de Strasbourg, 67087 Strasbourg, France

Valérie Caps - Institut de Chimie et Procédés pour l'Energie, l'Environnement et la Santé (ICPEES), ECPM, UMR 7515 CNRS - Université de Strasbourg, 67087 Strasbourg, France; orcid.org/0000-0001-9330-2566

Vasiliki Papaefthimiou - Institut de Chimie et Procédés pour l'Energie, l'Environnement et la Santé (ICPEES), ECPM, UMR 7515 CNRS - Université de Strasbourg, 67087 Strasbourg, France

Michael Haevecker - Max-Planck-Institut für Chemische Energiekonversion (MPI-CEC), D45470 Mülheim a.d. Ruhr, Germany; Fritz-Haber-Institut der Max-Planck- Gesellschaft, D14195 Berlin, Germany 
Detre Teschner - Max-Planck-Institut für Chemische Energiekonversion (MPI-CEC), D45470 Mülheim a.d. Ruhr, Germany; Fritz-Haber-Institut der Max-Planck-Gesellschaft, D14195 Berlin, Germany

Walid Baaziz - Institut de Physique et Chimie des Matériaux de Strasbourg (IPCMS), UMR 7504 CNRS - Université de Strasbourg, 67034 Strasbourg, France

Elisa Borfecchia - Department of Chemistry, INSTM Reference Center and NIS Centers, University of Torino, 10125 Torino, Italy; orcid.org/0000-0001-8374-8329

Luca Braglia - CNR-IOM, TASC Laboratory, 34149 Trieste, Italy

Notes

The authors declare no competing financial interest.

\section{- ACKNOWLEDGMENTS}

L.Z. would like to thank the China Scholarship Council (CSC) for supporting their studies at ICPEES. M.B. acknowledges financial support from Strasbourg University via the IdEX2018 (Post-doctorants) project. E.B. and L.B. acknowledge the support from PRIN-2017 MOSCATo, project no. 2017KKP5ZR. L.B. acknowledges the Nanoscience Foundry and Fine Analysis (NFFA-MIUR Italy Progetti Internazionali) facility. We thank Prof. C. Petit for the useful and constructive discussions, as well as M. Hashagen and Dr. T. Dintzer for the BET and SEM-EDS measurements, respectively. D. Chen's help during BESSY synchrotron measurements is greatly appreciated. D. H. Simonne, A. Martini, D. Salusso, and M. Signorile are acknowledged for their help during the in situ NEXAFS data collection on APE-HE and, with R. K. Shrestha, subsequent data treatment. We are also grateful to P. Torelli and G. Ricchiardi for their support during the measurements at APE-HE, as well as insightful discussions and advices. Finally, we acknowledge HZB for the allocation of synchrotron radiation beamtime and BESSY Synchrotron staff for the collaboration during the experiments.

\section{- REFERENCES}

(1) Madej-Lachowska, M.; Kulawska, M.; Słoczyński, J. Methanol as a High Purity Hydrogen Source for Fuel Cells: A Brief Review of Catalysts and Rate Expressions. Chem. Process Eng. 2017, 38, 147- 162 .

(2) Dawood, F.; Anda, M.; Shafiullah, G. M. Hydrogen Production for Energy: An Overview. Int. J. Hydrogen Energy 2020, 45, 3847-3869.

(3) Nazir, H.; Louis, C.; Jose, S.; Prakash, J.; Muthuswamy, N.; Buan, M. E. M.; Flox, C.; Chavan, S.; Shi, X.; Kauranen, P.; Kallio, T.; Maia, G.; Tammeveski, K.; Lymperopoulos, N.; Carcadea, E.; Veziroglu, E.; Iranzo, A.; Kannan, A. M. Is the H2 Economy Realizable in the Foreseeable Future? Part I: H2 Production Methods. Int. J. Hydrogen Energy 2020, 45, 13777-13788.

(4) Besancon, B. M.; Hasanov, V.; Imbault-Lastapis, R.; Benesch, R.; Barrio, M.; Mølnvik, M. J. Hydrogen Quality from Decarbonized Fossil Fuels to Fuel Cells. Int. J. Hydrogen Energy 2009, 34, 2350-2360. 
(5) Baschuk, J. J.; Li, X. Carbon Monoxide Poisoning of Proton Exchange Membrane Fuel Cells. Int. J. Energy Res. 2001, 25, 695-713.

(6) Li, K.; Zhou, L.; Liu, G. Integration of the Hydrogen-Storage Purification and Hydrogen Network. Ind. Eng. Chem. Res. 2020, 59, 10018-10030.

(7) Zhang, Y.; Zhang, G.; Wang, L.; Xu, Y.; Sun, Y. Selective Methanation of Carbon Monoxide over Ru-Based Catalysts in H2-Rich Gases. J. Ind. Eng. Chem. 2012, 18, $1590-1597$.

(8) Schorer, L.; Schmitz, S.; Weber, A. Membrane Based Purification of Hydrogen System (MEMPHYS). Int. J. Hydrogen Energy 2019, 44, 12708-12714.

(9) Badmaev, S. D.; Belyaev, V. D.; Konishcheva, M. V.; Kulikov, A. V.; Pechenkin, A. A.; Potemkin, D. I.; Rogozhnikov, V. N.; Snytnikov, P. V.; Sobyanin, V. A. Catalysts and Catalytic Processes for the Production of Hydrogen-Rich Gas for Fuel Cell Feeding. Chem. Probl. 2019, 17, 193-204.

(10) Cao, L.; Liu, W.; Luo, Q.; Yin, R.; Wang, B.; Weissenrieder, J.; Soldemo, M.; Yan, H.; Lin, Y.; Sun, Z.; Ma, C.; Zhang, W.; Chen, S.; Wang, H.; Guan, Q.; Yao, T.; Wei, S.; Yang, J.; Lu, J. Atomically Dispersed Iron Hydroxide Anchored on Pt for Preferential Oxidation of $\mathrm{CO}$ in $\mathrm{H} 2$. Nature 2019, 565, 631-635.

(11) Jing, P.; Gong, X.; Liu, B.; Zhang, J. Recent Advances in Synergistic Effect Promoted Catalysts for Preferential Oxidation of Carbon Monoxide. Catal. Sci. Technol. 2020, 10, 919-934.

(12) Liu, K.; Wang, A.; Zhang, T. Recent Advances in Preferential Oxidation of CO Reaction over Platinum Group Metal Catalysts. ACS Catal. 2012, 2, 1165-1178.

(13) Marie, O.; Portier, X.; Korsunska, N.; Khomenkova, L. CO- PROX Reactions on Copper Y2O3-ZrO2 Catalysts Prepared by a Single Step Co-Precipitation Technique. Appl. Catal. B Environ. 2020, 278, 119258.

(14) Gómez, L. E.; Sollier, B. M.; Lacoste, A. M.; Miró, E. E.; Boix, A. V. Hydrogen Purification for Fuel Cells through CO Preferential Oxidation Using PtCu/A12O3 Structured Catalysts. J. Environ. Chem. Eng. 2019, 7, 103376.

(15) Xie, X.; Li, Y.; Liu, Z. Q.; Haruta, M.; Shen, W. Low- Temperature Oxidation of CO Catalysed by Co3O4 Nanorods. Nature 2009, 458, 746-749.

(16) Gómez-Cuaspud, J. A.; Schmal, M. Nanostructured Metal Oxides Obtained by Means Polymerization-Combustion at Low Temperature for CO Selective Oxidation. Int. J. Hydrogen Energy 2013, 38, 7458-7468.

(17) Nguyen, L.; Tao, F. F.; Tang, Y.; Dou, J.; Bao, X. J. Understanding Catalyst Surfaces during Catalysis through Near Ambient Pressure X-Ray Photoelectron Spectroscopy. Chem. Rev. 2019, 119, 6822-6905.

(18) Zhong, L.; Chen, D.; Zafeiratos, S. A Mini Review of in Situ Near-Ambient Pressure XPS Studies on Non-Noble, Late Transition Metal Catalysts. Catal. Sci. Technol. 2019, 9, 3851-3867. 
(19) Huang, B.; Cao, K.; Liu, X.; Qian, L.; Shan, B.; Chen, R. Tuning the Morphology and Composition of Ultrathin Cobalt Oxide Films via Atomic Layer Deposition. RSC Adv. 2015, $5,71816-71823$.

(20) Kersell, H.; Hooshmand, Z.; Yan, G.; Le, D.; Nguyen, H.; Eren, B.; Wu, C. H.; Waluyo, I.; Hunt, A.; Nemšák, S.; Somorjai, G.; Rahman, T. S.; Sautet, P.; Salmeron, M. CO Oxidation Mechanisms on CoOx-Pt Thin Films. J. Am. Chem. Soc. 2020, 142, 8312-8322.

(21) Wu, C. H.; Liu, C.; Su, D.; Xin, H. L.; Fang, H.-T.; Eren, B.; Zhang, S.; Murray, C. B.; Salmeron, M. B. Bimetallic Synergy in Cobalt-Palladium Nanocatalysts for CO Oxidation. Nat. Catal. 2019, 2, 78-85.

(22) Sun, Y. N.; Giordano, L.; Goniakowski, J.; Lewandowski, M.; Qin, Z. H.; Noguera, C.; Shaikhutdinov, S.; Pacchioni, G.; Freund, H. J. The Interplay between Structure and CO Oxidation Catalysis on Metal-Supported Ultrathin Oxide Films. Angew. Chem., Int. Ed. 2010, $49,4418-4421$.

(23) Zhong, L.; Kropp, T.; Baaziz, W.; Ersen, O.; Teschner, D.; Schlögl, R.; Mavrikakis, M.; Zafeiratos, S. Correlation between Reactivity and Oxidation State of Cobalt Oxide Catalysts for CO Preferential Oxidation. ACS Catal. 2019, 9, 8325-8336.

(24) Zhou, G.; Xie, H.; Gui, B.; Zhang, G.; Zheng, X. Influence of NiO on the Performance of CoO-Based Catalysts for the Selective Oxidation of $\mathrm{CO}$ in $\mathrm{H}$ 2-Rich Gas. Catal. Commun. 2012, 19, 42-45.

(25) Teng, Y.; Sakurai, H.; Ueda, A.; Kobayashi, T. Oxidative Removal of Co Contained in Hydrogen by Using Metal Oxide Catalysts. Int. J. Hydrogen Energy 1999, 24, 355-358.

(26) Lukashuk, L.; Föttinger, K.; Kolar, E.; Rameshan, C.; Teschner, D.; Hävecker, M.; Knop-Gericke, A.; Yigit, N.; Li, H.; McDermott, E.; Stöger-Pollach, M.; Rupprechter, G. Operando XAS and NAP-XPS Studies of Preferential CO Oxidation on $\mathrm{Co} 3 \mathrm{O} 4$ and $\mathrm{CeO} 2$ Co3O4 Catalysts. J. Catal. 2016, 344, 1-15.

(27) Nyathi, T. M.; Fischer, N.; York, A. P. E.; Morgan, D. J.; Hutchings, G. J.; Gibson, E. K.; Wells, P. P.; Catlow, C. R. A.; Claeys, M. Impact of Nanoparticle-Support Interactions in Co3O4/A12O3 Catalysts for the Preferential Oxidation of Carbon Monoxide. ACS Catal. 2019, 9, 7166-7178.

(28) Nyathi, T. M.; Fischer, N.; York, A. P. E.; Claeys, M. Environment-Dependent Catalytic Performance and Phase Stability of $\mathrm{Co} 3 \mathrm{O} 4$ in the Preferential Oxidation of Carbon Monoxide Studied In Situ. ACS Catal. 2020, 10, 11892-11911.

(29) Woods, M. P.; Gawade, P.; Tan, B.; Ozkan, U. S. Preferential Oxidation of Carbon Monoxide on $\mathrm{Co} / \mathrm{CeO} 2$ nanoparticles. Appl. Catal. B Environ. 2010, 97, 28-35.

(30) Liu, J.; Jiang, L.; Zhang, B.; Jin, J.; Su, D. S.; Wang, S.; Sun, G. Controllable Synthesis of Cobalt Monoxide Nanoparticles and the Size-Dependent Activity for Oxygen Reduction Reaction. ACS Catal. 2014, 2998-3001.

(31) Papaefthimiou, V.; Dintzer, T.; Dupuis, V.; Tamion, A.; Tournus, F.; Hilion, A.; Teschner, D.; Hävecker, M.; Knop-Gericke, A.; Schlögl, R.; Zafeiratos, S. Nontrivial Redox Behavior of Nanosized Cobalt: New Insights from Ambient Pressure X-Ray Photoelectron and Absorption Spectroscopies. ACS Nano 2011, 5, 2182-2190. 
(32) Khasu, M.; Nyathi, T.; Morgan, D. J.; Hutchings, G. J.; Claeys, M.; Fischer, N. Co3O4 Morphology in the Preferential Oxidation of CO. Catal. Sci. Technol. 2017, 7, 4806-4817.

(33) Zhou, Y.; Jin, C.; Li, Y.; Shen, W. Dynamic Behavior of Metal Nanoparticles for Catalysis. Nano Today 2018, 20, 101-120.

(34) Papaefthimiou, V.; Dintzer, T.; Lebedeva, M.; Teschner, D.; Hävecker, M.; KnopGericke, A.; Schlögl, R.; Pierron-Bohnes, V.; Savinova, E.; Zafeiratos, S. Probing MetalSupport Interaction in Reactive Environments: An in Situ Study of PtCo Bimetallic Nanoparticles Supported on TiO2. J. Phys. Chem. C 2012, 116, 14342-14349.

(35) Zheng, F.; Alayoglu, S.; Guo, J.; Pushkarev, V.; Li, Y.; Glans, P.-A.; Chen, J.; Somorjai, G. In-Situ X-Ray Absorption Study of Evolution of Oxidation States and Structure of Cobalt in Co and CoPt Bimetallic Nanoparticles (4 Nm) under Reducing (H2) and Oxidizing (O2) Environments. Nano Lett. 2011, 11, 847-853.

(36) Abbate, M.; Pen, H.; Czyzyk, M. T.; de Groot, F. M. F.; Fuggle, J. C.; Ma, Y. J.; Chen, C. T.; Sette, F.; Fujimori, A.; Ueda, Y.; Kosuge, K. Soft X-Ray Absorption Spectroscopy of Vanadium Oxides. J. Electron Spectros. Relat. Phenomena 1993, 62, 185-195.

(37) Wang, K.; Liu, B.; Cao, Y.; Li, Y.; Jia, D. V-Modified Co3O4 Nanorods with Superior Catalytic Activity and Thermostability for CO Oxidation. CrystEngComm 2018, 20, 5191-5199.

(38) Wang, T.; Ding, Y.; Xiong, J.; Yan, L.; Zhu, H.; Lu, Y.; Lin, L. Effect of Vanadium Promotion on Activated Carbon-Supported Cobalt Catalysts in Fischer-Tropsch Synthesis. Catal. Letters 2006, 107, 47-52.

(39) Liu, D.; Ai, H.; Li, J.; Fang, M.; Chen, M.; Liu, D.; Du, X.; Zhou, P.; Li, F.; Lo, K. H.; Tang, Y.; Chen, S.; Wang, L.; Xing, G.; Pan, H. Surface Reconstruction and Phase Transition on Vanadium-Cobalt-Iron Trimetal Nitrides to Form Active Oxyhydroxide for Enhanced Electrocatalytic Water Oxidation. Adv. Energy Mater. 2020, 10, 2002464.

(40) Bao, T.; Zhao, Z.; Dai, Y.; Lin, X.; Jin, R.; Wang, G.; Muhammad, T. Supported Co 30 4-CeO 2 Catalysts on Modified Activated Carbon for CO Preferential Oxidation in H 2-Rich Gases. Appl. Catal. B Environ. 2012, 119-120, 62-73.

(41) Zhao, Z.; Lin, X.; Jin, R.; Wang, G.; Muhammad, T. MOx (M=Mn, Fe, Ni or Cr) Improved Supported Co $3 \mathrm{O} 4$ Catalysts on Ceria-Zirconia Nanoparticulate for CO Preferential Oxidation in H2- Rich Gases. Appl. Catal. B Environ. 2012, 115-116, 53-62.

(42) Couvret, G.; Genay, G.; Robert, C.; Michel, L.; Caps, V. Intercalation of Copper Phthalocyanine Within Bulk Graphite as a New Strategy Toward the Synthesis of CuO-Based CO Oxidation Catalysts. Front. Chem. 2020, 8, 735.

(43) Potemkin, D. I.; Filatov, E. Y.; Zadesenets, A. V.; Gorlova, A. M.; Nikitina, N. A.; Pichugina, D. A. A Comparative Study of CO Preferential Oxidation over Pt and Pt0.5Co0.5 Nanoparticles: Kinetic Study and Quantum-Chemical Calculations. Mater. Lett. 2020, 260, 126915.

(44) Barroso-Martín, I.; Alberoni, C.; Rodríguez-Castellón, E.; Infantes-Molina, A.; Moretti, E. Recent Advances in Photo-Assisted Preferential CO Oxidation in H2-Rich Stream. Curr. Opin. Green Sustain. Chem. 2020, 21, 9-15. 
(45) Follath, R.; Hävecker, M.; Reichardt, G.; Lips, K.; Bahrdt, J.; Schäfers, F.; Schmid, P. The Energy Materials In-Situ Laboratory Berlin (EMIL) at BESSY II. In Journal of Physics: Conference Series; 2013; p 212003.

(46) Hendel, S.; Schäfers, F.; Hävecker, M.; Reichardt, G.; Scheer, M.; Bahrdt, J.; Lips, K. The EMIL Project at BESSY II: Beamline Design and Performance. In AIP Conference Proceedings 1741; 2016; p 030038.

(47) Zafeiratos, S.; Dintzer, T.; Teschner, D.; Blume, R.; Hävecker, M.; Knop-Gericke, A.; Schlögl, R. Methanol Oxidation over Model Cobalt Catalysts: Influence of the Cobalt Oxidation State on the Reactivity. J. Catal. 2010, 269, 309-317.

(48) Lykhach, Y.; Piccinin, S.; Skála, T.; Bertram, M.; Tsud, N.; Brummel, O.; Farnesi Camellone, M.; Beranová, K.; Neitzel, A.; Fabris, S.; Prince, K. C.; Matolín, V.; Libuda, J. Quantitative Analysis of the Oxidation State of Cobalt Oxides by Resonant Photoemission Spectroscopy. J. Phys. Chem. Lett. 2019, 10, 6129-6136.

(49) Yeh, J. J.; Lindau, I. Atomic Subshell Photoionization Cross Sections and Asymmetry Parameters: $1<Z<103$. At. Data Nucl. Data Tables 1985, 32, 1-155.

(50) Smekal, W.; Werner, W. S. M.; Powell, C. J. Simulation of Electron Spectra for Surface Analysis (SESSA): A Novel Software Tool for Quantitative Auger-Electron Spectroscopy and X-Ray Photoelectron Spectroscopy. Surf. Interface Anal. 2005, 37, 1059- 1067.

(51) Groot, F. D. Multiplet Effects in X-Ray Spectroscopy. Coord. Chem. Rev. 2005, 249, $31-63$.

(52) De Groot, F. High-Resolution X-Ray Emission and X-Ray Absorption Spectroscopy. Chem. Rev. 2001, 101, 1779-1808.

(53) Stavitski, E.; de Groot, F. M. F. The CTM4XAS Program for EELS and XAS Spectral Shape Analysis of Transition Metal L Edges. Micron 2010, 41, 687-694.

(54) Laverock, J.; Chen, B.; Preston, A. R. H.; Smith, K. E.; Wilson, N. R.; Balakrishnan, G.; Glans, P. A.; Guo, J.-H. Electronic Structure of the Kagome Staircase Compounds Ni3V 208 and Co3V2O8. Phys. Rev. B - Condens. Matter Mater. Phys. 2013, 87, 125133.

(55) Laverock, J.; Preston, A. R. H.; Chen, B.; McNulty, J.; Smith, K. E.; Piper, L. F. J.; Glans, P. A.; Guo, J. H.; Marin, C.; Janod, E.; Ta Phuoc, V. Orbital Anisotropy and LowEnergy Excitations of the Quasi-One-Dimensional Conductor $\beta$-Sr0.17V2O5. Phys. Rev. B Condens. Matter Mater. Phys. 2011, 84, 155103.

(56) Castán-Guerrero, C.; Krizmancic, D.; Bonanni, V.; Edla, R.; Deluisa, A.; Salvador, F.; Rossi, G.; Panaccione, G.; Torelli, P. A Reaction Cell for Ambient Pressure Soft X-Ray Absorption Spectroscopy. Rev. Sci. Instrum. 2018, 89, No. 054101.

(57) Simonne, D. H.; Martini, A.; Signorile, M.; Piovano, A.; Braglia, L.; Torelli, P.; Borfecchia, E.; Ricchiardi, G. THORONDOR : A Software for Fast Treatment and Analysis of Low-Energy XAS Data. J. Synchrotron Radiat. 2020, 27, 1741-1752.

(58) Nguyen, T. S.; Morfin, F.; Aouine, M.; Bosselet, F.; Rousset, J. L.; Piccolo, L. Trends in the CO Oxidation and PROX Performances of the Platinum-Group Metals Supported on Ceria. Catal. Today 2015, 253, 106-114. 
(59) Zhang, Q.; Liu, X.; Fan, W.; Wang, Y. Manganese-Promoted Cobalt Oxide as Efficient and Stable Non-Noble Metal Catalyst for Preferential Oxidation of CO in H2 Stream. Appl. Catal. B Environ. 2011, 102, 207-214.

(60) Lee, H. C.; Kim, D. H. Kinetics of $\mathrm{CO}$ and $\mathrm{H} 2$ Oxidation over $\mathrm{CuO}-\mathrm{CeO} 2$ Catalyst in $\mathrm{H} 2$ Mixtures with CO2 and H2O. Catal. Today 2008, 132, 109-116.

(61) Landi, G.; Di Benedetto, A.; Lisi, L. Two-Stage Strategy for CO Removal from H2-Rich Streams over (Nano-) CuO/CeO2 Structured Catalyst at Low Temperature. Appl. Sci. 2018, 8, 789.

(62) Natile, M. M.; Glisenti, A. Study of Surface Reactivity of Cobalt Oxides: Interaction with Methanol. Chem. Mater. 2002, 14, 3090-3099.

(63) Ward, M. R.; Boyes, E. D.; Gai, P. L. In Situ Aberration- Corrected Environmental TEM: Reduction of Model Co3O4 in $\mathrm{H} 2$ at the Atomic Level. ChemCatChem 2013, 5, 2655-2661.

(64) Van Steen, E.; Sewell, G. S.; Makhothe, R. A.; Micklethwaite, C.; Manstein, H.; De Lange, M.; O'Connor, C. T. TPR Study on the Preparation of Impregnated Co/SiO2 Catalysts. J. Catal. 1996, 162, 220-229.

(65) Deng, W.; Tang, Q.; Huang, S.; Zhang, L.; Jia, Z.; Guo, L. Low Temperature Catalytic Combustion of Chlorobenzene over Cobalt Based Mixed Oxides Derived from Layered Double Hydroxides. Appl. Catal. B Environ. 2020, 278, 119336.

(66) Nguyen, L.; Zhang, S.; Yoon, S. J.; Tao, F. F. Preferential Oxidation of CO in H 2 on Pure Co 3 O 4- $\mathrm{x}$ and Pt/Co 3 O 4-X. ChemCatChem 2015, 7, 2346-2353.

(67) Guo, Q.; Liu, Y. MnOx Modified Co3O4-CeO2 Catalysts for the Preferential Oxidation of CO in H2-Rich Gases. Appl. Catal. B Environ. 2008, 82, 19-26.

(68) Grzybek, G.; Ciura, K.; Gryboś, J.; Indyka, P.; Davó-Quiñonero, A.; Lozano-Castelló, D.; Bueno-Lopez, A.; Kotarba, A.; Sojka, Z. COPROX Reaction over Co3O4|Al2O3 Catalysts - Impact of the Spinel Active Phase Faceting on the Catalytic Performance. J. Phys. Chem. C 2019, 123, 20221-20232.

(69) Zhang, F.; Liu, Z.; Zhang, S.; Akter, N.; Palomino, R. M.; Vovchok, D.; Orozco, I.; Salazar, D.; Rodriguez, J. A.; Llorca, J.; Lee, J.; Kim, D. H.; Xu, W.; Frenkel, A. I.; Li, Y.; Kim, T.; Senanayake, S. D. In Situ Elucidation of the Active State of Co-CeOx Catalysts in the Dry Reforming of Methane: The Important Role of the Reducible Oxide Support and Interactions with Cobalt. ACS Catal. 2018, 8, 3550-3560.

(70) Lukashuk, L.; Yigit, N.; Li, H.; Bernardi, J.; Föttinger, K.; Rupprechter, G. Operando XAS and NAP-XPS Investigation of CO Oxidation on Meso- and Nanoscale CoO Catalysts. Catal. Today 2019, 336, 139-147.

(71) Kosmala, T.; Calvillo, L.; Agnoli, S.; Granozzi, G. Enhancing the Oxygen Electroreduction Activity through Electron Tunnelling: CoOx Ultrathin Films on Pd(100). ACS Catal. 2018, 8, 2343-2352. 
(72) Tang, Y.; Ma, L.; Dou, J.; Andolina, C. M.; Li, Y.; Ma, H.; House, S. D.; Zhang, X.; Yang, J.; Tao, F. Transition of Surface Phase of Cobalt Oxide during CO Oxidation. Phys. Chem. Chem. Phys. 2018, 20, 6440-6449.

(73) Petitto, S. C.; Marsh, E. M.; Carson, G. A.; Langell, M. A. Cobalt Oxide Surface Chemistry: The Interaction of $\mathrm{CoO}\left(\begin{array}{lll}1 & 0 & 0\end{array}\right), \mathrm{Co3O} 4\left(\begin{array}{lll}1 & 1 & 0\end{array}\right)$ and $\mathrm{Co} 3 \mathrm{O} 4\left(\begin{array}{lll}1 & 1 & 1\end{array}\right)$ with Oxygen and Water. J. Mol. Catal. A: Chem. 2008, 281, 49-58.

(74) Chen, J. G.; Eng, J.; Kelty, S. P. NEXAFS Determination of Electronic and Catalytic Properties of Transition Metal Carbides and Nitrides: From Single Crystal Surfaces to Powder Catalysts. Catal. Today 1998, 43, 147-158.

(75) Joachim, Stöhr. NEXAFS Spectroscopy, Surface Sc.; Robert, Gomer, Ed.; Springer, 1996.

(76) Biener, J.; Bäumer, M.; Madix, R. J.; Liu, P.; Nelson, E.; Kendelewisz, T.; Brown, G., Jr. Growth and Electronic Structure of Vanadium on $\alpha$-Al2O3(0001). Surf. Sci. 2000, 449, $50-60$.

(77) Chen, J. G. NEXAFS Investigations of Transition Metal Oxides, Nitrides, Carbides, Sulfides and Other Interstitial Compounds. Surf. Sci. Rep. 1997, 30, 1-152.

(78) Turczyniak, S.; Luo, W.; Papaefthimiou, V.; Ramgir, N. S.; Haevecker, M.; MacHocki, A.; Zafeiratos, S. A Comparative Ambient Pressure X-Ray Photoelectron and Absorption Spectroscopy Study of Various Cobalt-Based Catalysts in Reactive Atmospheres. Top. Catal. 2016, 59, 532-542.

(79) Xing, M.; Kong, L. B.; Liu, M. C.; Liu, L. Y.; Kang, L.; Luo, Y. C. Cobalt Vanadate as Highly Active, Stable, Noble Metal-Free Oxygen Evolution Electrocatalyst. J. Mater. Chem. A 2014, 2, 18435-18443.

(80) Chakrapani, K.; Bendt, G.; Hajiyani, H.; Lunkenbein, T.; Greiner, M. T.; Masliuk, L.; Salamon, S.; Landers, J.; Schlögl, R.; Wende, H.; Pentcheva, R.; Schulz, S.; Behrens, M. The Role of Composition of Uniform and Highly Dispersed Cobalt Vanadium Iron Spinel Nanocrystals for Oxygen Electrocatalysis. ACS Catal. 2018, 8, 1259-1267.

(81) Mu, C.; Mao, J.; Guo, J.; Guo, Q.; Li, Z.; Qin, W.; Hu, Z.; Davey, K.; Ling, T.; Qiao, S. Z. Rational Design of Spinel Cobalt Vanadate Oxide Co2VO4 for Superior Electrocatalysis. Adv. Mater. 2020, 32, 1-8.

(82) Nonaka, Y.; Shibata, G.; Koborinai, R.; Ishigami, K.; Sakamoto, S.; Ikeda, K.; Chi, Z.; Koide, T.; Tanaka, A.; Katsufuji, T.; Fujimori, A. Electronic States and Possible Origin of the Orbital-Glass State in a Nearly Metallic Spinel Cobalt Vanadate: An x-Ray Magnetic Circular Dichroism Study. Phys. Rev. B 2018, 97, 1-7.

(83) Gómez, L. E.; Tiscornia, I. S.; Boix, A. V.; Miró, E. E. Co/ZrO2 Catalysts Coated on Cordierite Monoliths for CO Preferential Oxidation. Appl. Catal. A Gen. 2011, 401, 124-133.

(84) Bora, D. K.; Cheng, X.; Kapilashrami, M.; Glans, P. A.; Luo, Y.; Guo, J. H. Influence of Crystal Structure, Ligand Environment and Morphology on Co L-Edge XAS Spectral Characteristics in Cobalt Compounds. J. Synchrotron Radiat. 2015, 22, 1450-1458. 
(85) Liu, B.; Glass, E. N.; Wang, R. P.; Cui, Y. T.; Harada, Y.; Huang, D. J.; Schuppler, S.; Hill, C. L.; De Groot, F. M. F. Cobalt-to-Vanadium Charge Transfer in Polyoxometalate Water Oxidation Catalysts Revealed by 2p3d Resonant Inelastic X-Ray Scattering. Phys. Chem. Chem. Phys. 2018, 20, 4554-4562.

(86) Wang, Q.; Madix, R. J. Preparation and Reactions of V2O5 Supported on TiO2 (110). Surf. Sci. 2001, 474, L213-L216.

(87) Guimond, S.; Göbke, D.; Romanyshyn, Y.; Sturm, J. M.; Naschitzki, M.; Kuhlenbeck, H.; Freund, H. J. Growth and Characterization of Ultrathin V2Oy (y $\approx 5)$ Films on $\mathrm{Au}(111)$. J. Phys. Chem. C 2008, 112, 12363-12373.

(88) Silversmit, G.; Depla, D.; Poelman, H.; Marin, G. B.; De Gryse, R. Determination of the V2p XPS Binding Energies for Different Vanadium Oxidation States (V5+ to V0+). J. Electron Spectros. Relat. Phenomena 2004, 135, 167-175.

(89) Beke, S. A Review of the Growth of V2O5 Films from 1885 to 2010. Thin Solid Films 2011, 519, 1761-1771.

(90) Brik, M. G.; Ogasawara, K.; Ikeno, H.; Tanaka, I. Fully Relativistic Calculations of the L2,3-Edge XANES Spectra for Vanadium Oxides. Eur. Phys. J. B 2006, 51, 345-355.

(91) Maganas, D.; Roemelt, M.; Weyhermüller, T.; Blume, R.; Hävecker, M.; Knop-Gericke, A.; Debeer, S.; Schlögl, R.; Neese, F. Ledge X-Ray Absorption Study of Mononuclear Vanadium Complexes and Spectral Predictions Using a Restricted Open Shell Configuration Interaction Ansatz. Phys. Chem. Chem. Phys. 2014, 16, 264-276.

(92) Hävecker, M.; Knop-Gericke, A.; Mayer, R. W.; Fait, M.; Bluhm, H.; Schlögl, R. Influence of the Geometric Structure on the V L3 near Edge X-Ray Absorption Fine Structure from Vanadium Phosphorus Oxide Catalysts. J. Electron Spectros. Relat. Phenomena 2002, $125,79-87$.

(93) Taftø, J.; Krivanek, O. L. Site-Specific Valence Determination by Electron Energy-Loss Spectroscopy. Phys. Rev. Lett. 1982, 48, 560-563.

(94) Maganas, D.; Roemelt, M.; Hävecker, M.; Trunschke, A.; Knop-Gericke, A.; Schlögl, R.; Neese, F. First Principles Calculations of the Structure and v L-Edge X-Ray Absorption Spectra of V2O5 Using Local Pair Natural Orbital Coupled Cluster Theory and Spin-Orbit Coupled Configuration Interaction Approaches. Phys. Chem. Chem. Phys. 2013, 15, $7260-7276$.

(95) Papaefthimiou, V.; Dintzer, T.; Dupuis, V.; Tamion, A.; Tournus, F.; Teschner, D.; Hävecker, M.; Knop-Gericke, A.; Schlögl, R.; Zafeiratos, S. S. When a Metastable Oxide Stabilizes at the Nanoscale: Wurtzite CoO Formation upon Dealloying of PtCo Nanoparticles. J. Phys. Chem. Lett. 2011, 2, 900-904.

(96) Papaefthimiou, V.; Tournus, F.; Hillion, A.; Khadra, G.; Teschner, D.; Knop-Gericke, A.; Dupuis, V.; Zafeiratos, S. Mixing Patterns and Redox Properties of Iron-Based Alloy Nanoparticles under Oxidation and Reduction Conditions. Chem. Mater. 2014, 26, $1553-1560$. 
(97) Doh, W. H.; Papaefthimiou, V.; Dintzer, T.; Dupuis, V.; Zafeiratos, S. Synchrotron Radiation X-Ray Photoelectron Spectroscopy as a Tool to Resolve the Dimensions of Spherical Core/Shell Nanoparticles. J. Phys. Chem. C 2014, 118, 26621-26628.

(98) Chenakin, S. P.; Szukiewicz, R.; Barbosa, R.; Kruse, N. Surface Analysis of Transition Metal Oxalates: Damage Aspects. J. Electron Spectros. Relat. Phenomena 2016, 209, 66-77.

(99) Chenakin, S.; Kruse, N. XPS Characterization of Transition Metal Oxalates. Appl. Surf. Sci. 2020, 515, 146041.

(100) Zhao, H.; Bennici, S.; Shen, J.; Auroux, A. Nature of Surface Sites of V2O5 TiO2/SO42- Catalysts and Reactivity in Selective Oxidation of Methanol to Dimethoxymethane. J. Catal. 2010, 272, 176-189.

(101) Zhang, X. Q.; Chen, Y. S.; Kamat, P. V.; Ptasinska, S. Probing Interfacial Electrochemistry on a Co3O4 Water Oxidation Catalyst Using Lab-Based Ambient Pressure X-Ray Photoelectron Spectroscopy. J. Phys. Chem. C 2018, 122, 13894-13901.

(102) Zafeiratos, S.; Paloukis, F.; Papakonstantinou, G.; Teschner, D.; Hävecker, M.; Vass, E.; Schnörch, P.; Knop-Gericke, A.; Schlogl, R.; Moreno, B.; Chinarro, E.; Jurado, J. R.; Neophytides, S. G. A Comparative in Situ XPS Study of PtRuCo Catalyst in Methanol Steam Reforming and Water Gas Shift Reactions. Catal. Today 2010, 157, 250-256.

(103) Lukashuk, L.; Yigit, N.; Rameshan, R.; Kolar, E.; Teschner, D.; Hävecker, M.; KnopGericke, A.; Schlögl, R.; Föttinger, K.; Rupprechter, G. Operando Insights into CO Oxidation on Cobalt Oxide Catalysts by NAP-XPS, FTIR, and XRD. ACS Catal. 2018, 8, 8630-8641.

(104) Hävecker, M.; Düngen, P.; Buller, S.; Knop-Gericke, A.; Trunschke, A.; Schlögl, R. Restructuring of Silica Supported Vanadia during Propane Oxidative Dehydrogenation Studied by Combined Synchrotron Radiation Based in Situ Soft X-Ray Absorption and Photoemission. Catal. Struct. React. 2017, 3, 104-111.

(105) Kuld, S.; Thorhauge, M.; Falsig, H.; Elkjær, C. F.; Helveg, S.; Chorkendorff, I.; Sehested, J. Quantifying the Promotion of $\mathrm{Cu}$ Catalysts by $\mathrm{ZnO}$ for Methanol Synthesis. Science 2016, 352, 969-974.

(106) Ha, D. H.; Moreau, L. M.; Honrao, S.; Hennig, R. G.; Robinson, R. D. The Oxidation of Cobalt Nanoparticles into Kirkendall-Hollowed CoO and Co3O4: The Diffusion Mechanisms and Atomic Structural Transformations. J. Phys. Chem. C 2013, 117, 14303-14312.

(107) Baidya, T.; Murayama, T.; Bera, P.; Safonova, O. V.; Steiger, P.; Katiyar, N. K.; Biswas, K.; Haruta, M. Low-Temperature CO Oxidation over Combustion Made Fe- and CrDoped Co3O4 Catalysts: Role of Dopant's Nature toward Achieving Superior Catalytic Activity and Stability. J. Phys. Chem. C 2017, 217, 15256-15265.

(108) Moltved, K. A.; Kepp, K. P. The Chemical Bond between Transition Metals and Oxygen: Electronegativity, d-Orbital Effects, and Oxophilicity as Descriptors of MetalOxygen Interactions. J. Phys. Chem. C 2019, 123, 18432-18444.

(109) Védrine, J. C.; Fechete, I. Heterogeneous Partial Oxidation Catalysis on Metal Oxides. Comptes Rendus Chim. 2016, 19, 1203-1225. 